\title{
Equilibrium Parallel IMport Policies and INTERnational MARKet
}

STRUCTURE

by

Santanu Roy and Kamal Saggi

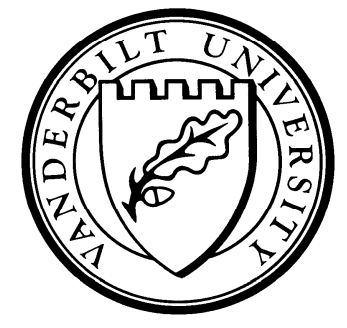

Working Paper No. 11-W13

September 2011

DEPARTMENT OF ECONOMICS

VANDERBILT UNIVERSITY

NASHVILLE, TN 37235

www.vanderbilt.edu/econ 


\title{
Equilibrium parallel import policies and international market structure*
}

\author{
Santanu Roy ${ }^{\dagger}$ \\ Southern Methodist University, Dallas, TX. \\ Kamal Saggi ${ }^{\ddagger}$ \\ Vanderbilt University, Nashville, TN.
}

First version: October 2009. This version: July 2011.

\begin{abstract}
In a North-South vertically differentiated duopoly, we derive equilibrium government policies towards parallel imports (PIs). By incorporating strategic interaction at the policysetting stage and the product market, the model sheds new light on $(i)$ the effects of PI policies on pricing behavior of firms and (ii) the interdependence of national PI policies. If demand asymmetry across countries is sufficiently large, the North forbids PIs to ensure its firm sells in the South thereby generating international price discrimination - the South's most preferred market outcome - as the equilibrium. When demand structures are relatively similar across countries, the North permits PIs and uniform pricing - its most preferred market outcome - obtains.
\end{abstract}

Keywords: Parallel Imports, Oligopoly, Quality, Product Differentiation, Market Structure, Welfare, Trade Policy. JEL Classifications: F13, F10, F15.

\footnotetext{
${ }^{*}$ For helpful comments and discussions, we thank two anonymous referees, co-editor Bob Staiger, Kyle Bagwell, Petros Mavroidis, Hodaka Morita, Nathan Nunn, Abhijit Sengupta, seminar audiences at Princeton, St. Louis Fed, Stanford, UC-Santa Cruz, the University of Sydney, the University of New South Wales, Vanderbilt, the Spring 2010 Midwest International Economics Meeting, and the Stony Brook 2011 Workshop on the Applications of Game Theory to Trade and Development. Parts of this paper were written during Kamal Saggi's visits to the Stanford Center for International Development (SCID) and the World Bank's Development Economics Research Group in Trade and Integration (DECTI); he is grateful to the affiliated researchers and the administrative staff of SCID and DECTI for their hospitality and support.

${ }^{\dagger}$ Address: Department of Economics, Southern Methodist University, 3300 Dyer Street, Dallas, TX 752750496, USA. E-mail: sroy@smu.edu; Tel: (+1) 2147682714.

${ }^{\ddagger}$ Corresponding Author. Address: Department of Economics, Vanderbilt University, Box 1819-Station B, Nashville, TN 37235-1819, USA. E-mail: k.saggi@Vanderbilt.Edu; phone: (+1) 615-322-3237.
} 


\section{Introduction}

Parallel trade is said to occur when a product protected by some form of intellectual property right (IPR) offered for sale by the rights holder in one country is re-sold in another country without the right holder's consent. As is clear, the incentive to engage in such trade naturally arises in the presence of significant international price differences, which in turn often reflect the underlying market power of sellers (Scherer and Watal, 2002).

The possibility of parallel trade affects firm behavior and pricing in the markets for many products such as books, CDs, DVDs, software, and surprisingly, even cars. For example, an article published in the New York Times on March 27, 1999 noted that "American entrepreneurs have been buying tens of thousands of vehicles cheaply at Canadian dealerships and reselling them in the United States" and that "most of the vehicles being brought South are large and built in the United States" i.e. these imports of cars from Canada were essentially parallel imports (PIs) of cars originally exported by the United States. ${ }^{1}$ The importance of PIs in the auto market in 1998 can be gauged from the fact that of the 74,413 vehicles brought into the United States that year, all but 400 or so came from Canada.

Perhaps the industry most affected by the possibility of PIs is the pharmaceutical industry. A recent article published in the Financial Times noted that several billion dollars of parallel trade in pharmaceuticals occurs within the European Union (EU) annually and that such trade accounts for roughly $10 \%$ of Europe's medicine trade. ${ }^{2}$ The biggest destination markets tend to be Germany, UK, Netherlands, Denmark, Sweden, Ireland, and Norway - some of the richest countries in Europe where prices generally tend to be the highest. As one might expect, the important parallel exporters are Greece and Spain - countries where prices of medicines are lower than the EU average. Kanavos et. al. (2004) carefully document the increased importance of PIs in the EU pharmaceutical market. They find that from 1997 to 2002, the share of PIs as a percentage of the total pharmaceutical market increased from under $2 \%$ to

\footnotetext{
${ }^{1}$ See "Market Grows For U.S. Cars from Canada" New York Times, March 27, 1999. This article also noted that such parallel trade in cars was common in Europe and that automakers such as Honda and Ford had managed to control PIs through technological and price measures. Honda, in particular, had managed to clamp down severely on PIs from Canada.

${ }^{2}$ See "European drug groups fear parallel trade" Financial Times, June 7, 2010.
} 
$10.1 \%$ in Sweden and from $1.7 \%$ to about $7 \%$ in Germany. On the export side, Greece's share of parallel exports increased from under $1 \%$ to $21.6 \%$ over the same time period.

It is worth emphasizing that when PIs are driven by the existence of price differentials, the observed flows of parallel trade do not need to be large for PI policies to matter because firms will tend to make different pricing decisions when such trade is permitted relative to when it is not. Indeed, one would expect PI policies to affect market outcomes primarily via their impact on the pricing behavior of firms as opposed to the volume of parallel trade. In this regard, it is noteworthy that Ganslandt and Maskus (2004) found that after Sweden joined the EU and opened its market to PIs, prices of drugs subject to competition from PI declined $12-19 \%$.

Discussions regarding PI policies tend to be especially charged in the context of pharmaceuticals and perhaps for good reason. ${ }^{3}$ In this regard, it is worth noting that Goldberg (2009) has argued that the practice of "global reference pricing" on the part of some rich countries and the possibility of PIs can induce pharmaceutical multinationals to not serve low income countries and/or raise their prices (even above their optimal monopoly prices) in such markets - outcomes that emerge quite sharply in our model. ${ }^{4}$

Whether or not PIs can flow into a country in a particular market is a matter of national policy. A country can choose to permit PIs in a market by adopting the legal doctrine of international exhaustion of IPRs under which such rights are deemed to expire globally with the first sale of the relevant product, regardless of the geographical incidence of the sale. On the other hand, a country can effectively ban PIs by adopting national exhaustion of IPRs wherein rights are held to expire only in the market of first sale thereby leaving the right

\footnotetext{
${ }^{3}$ The issue has also been heavily politicized in most countries, including the United States where it has been debated repeatedly over the years in Congress. For example, an article published in the Wall Street Journal on Dec 16, 2009 reported that a measure to allow importation of prescription drugs from abroad fell short in the US Senate by just 9 votes. The bill was sponsored by Senator Byron Dorgan of North Dakota who argued that his motivation was to protect consumer interests since "...the American people are charged the highest prices in the World". The pharmaceutical industry opposed the bill questioning the safety of imported drugs. While safety maybe a legitimate concern, there is little doubt that the primary issue for firms is the ability to maintain high prices in the United States.

${ }^{4}$ For empirical evidence on how pricing regulations affect the extent and the timing of drug launches in world markets by pharmaceutical multinationals, see Danzon and Epstein (2008), Danzon et. al. (2005), and Lanjouw (2005).
} 
holder free to prevent its resale in other markets.

While national laws pertaining to parallel trade are complex and multi-faceted, the following characterization broadly captures the global policy spectrum for the case of pharmaceuticals: the two largest markets in the world - i.e. United States and the EU - forbid PIs from most other countries whereas developing countries tend to vary widely in their restraints on such imports (Maskus, 2000). ${ }^{5}$ This variation in national PI policies reflects unilateral policy decisions since presently there is no multilateral cooperation or consensus over policies pertaining to parallel trade. Indeed, the key multilateral agreement on IPRs - i.e. the WTO's Agreement on Trade Related Aspects of Intellectual Property Rights (TRIPS) - leaves member countries free to implement PI policies of their choice.

Given the lack of any multilateral consensus regarding the desirability of parallel trade, two important questions arise. First, how do national PI policies affect strategic interaction among international firms? Second, what is the nature of strategic interdependence between PI policies of individual countries? To the best of our knowledge, ours is the first paper to provide an analysis of PI policies in a setting where there is strategic interaction not only in the product market but also at the policy-setting stage. We develop a North-South model in which the two regions differ with respect to their domestic demand structure as well as the quality of goods produced by their respective firms. In particular, the Northern firm's product is of high quality and the Southern firm's product is of low quality. Further, market size as well as the relative preference for high quality (i.e. the quality premium consumers are willing to pay) is higher in the North than in the South. Not only do these stylized asymmetries capture empirically relevant differences between Northern and Southern markets, we show that they shed new light on the causes and consequence of parallel trade. Furthermore, we argue that without properly accounting for such asymmetries, it is difficult to explain the observed variation in PI policies across countries.

\footnotetext{
${ }^{5}$ Maskus (2000) describes the policy variation among developing countries as follows: "...some nations disallow PI because their patent laws provide a strict right of importation to authorized licensees; these laws are common in countries with British or French colonial legacies. Moreover, several developing nations have laws permitting only one national distributor for products imported under trademark, effectively banning parallel imports... India follows a regime of international exhaustion in trademarked and patented goods. A number of developing countries including Argentina, Thailand, and South Africa, recently have enacted laws permitting parallel imports of pharmaceutical products."
} 
The timing of decisions in our model is as follows. First, governments simultaneously decide whether or not to permit PIs. Next, each firm chooses whether or not to offer its product for sale in the foreign market - i.e. the decision to export is endogenous in our model. Finally, given policies and market structure, firms compete in prices and international trade and consumption occur.

The existing literature on PIs has extensively explored the effects of uniform global pricing or international price discrimination by firms with market power. In addition to these symmetric market outcomes, an asymmetric market structure where the high quality firm refrains from selling in the South plays a crucial role in our analysis. Such a market structure can arise in our model because firms have uneven export incentives: the lure of the lucrative Northern market is stronger than that of the Southern market. We find that the strategic price competition between firms under such a market structure tends to be rather subtle. To gain further insight, suppose the North permits PIs while the South does not. Under such a policy configuration, if the relative preference for high quality in the North is not too high compared to that in the South, the low quality (Southern) firm charges its optimal monopoly price locally while both firms charge their optimal discriminatory prices in the larger Northern market. However, if the relative preference for high quality in the North is sufficiently higher than in the South, the low quality firm's optimal monopoly price in the South is lower than its optimal discriminatory price for the Northern market. Under such a scenario, the North's openness to PIs induces the low quality firm to set a common international price that actually exceeds its optimal monopoly price for the Southern market: i.e. it tolerates a sub-optimally high price in the Southern market to charge a more attractive price in the Northern market. The resulting softening of price competition in the Northern market, in turn, makes forsaking the Southern market more attractive for the Northern firm, especially considering the fact that the local demand for its high quality product is relatively large. Indeed, we show that such an asymmetric market structure can arise not only when only one country permits PIs but also when both countries do so.

Our policy analysis sheds light on how the underlying heterogeneity in demand structure across countries determines national preferences for PI policies. Assuming governments max- 
imize national welfare, we show that the North is more likely to permit PIs (i.e. it prefers to permit PIs over a larger parameter space) when the South does not do so. With its smaller market, the Southern government's influence on market structure tends to be weaker, something that is reflected in the nature of policy equilibrium: if the North is open to PIs, the South also (weakly) prefers to be open to PIs whereas a Northern ban on PIs makes the South indifferent between its two policy options since it renders the Southern policy inconsequential for market structure.

We find that when the relative preference for high quality in the North is sufficiently higher than that in the South, in equilibrium, the Northern government chooses to forbid PIs. This result accords quite well with the type of PI policies we observe in the world: recall that the two largest markets in the world - the EU and the USA - prohibit PIs from most of the rest of the world. The intuition for this result is that by inducing international market segmentation and shielding its firm from the threat of indirect competition from arbitrage-induced PIs, the Northern prohibition on PIs ensures that its firm chooses to directly compete in the Southern market.

This policy result is noteworthy for several reasons. First, it is surprising since North's welfare under uniform pricing is strictly higher than that under price discrimination. So why doesn't the North simply permit PIs? As was noted earlier, if the North permits PIs and markets are sufficiently different in preference for high quality, uniform pricing does not emerge as an equilibrium market structure. Rather, under such circumstances the high quality firm abstains from serving the less lucrative Southern market in order to charge a higher price in the Northern market, an outcome that is detrimental for Northern consumers and overall Northern welfare. To avoid such an outcome, the North is better off prohibiting PIs: while international price discrimination is not as desirable to the North as uniform pricing, it is preferable to asymmetric market structures under which it's firm abstains from selling in the South. The second noteworthy aspect of this result is that a unilateral prohibition on PIs by the North generates a substantial positive spillover for the South: not only do Southern consumers enjoy lower prices for both goods under international price discrimination, the low quality firm also benefits from being able to charge a higher price in the Northern market. 
Finally, we show that when markets are relatively similar in size and preference for high quality, the North permits PIs and uniform pricing obtains. Thus, only when its firm is reluctant to opt out of the Southern market can the North implement a policy that yields its most preferred market outcome. Furthermore, when demand is fully symmetric across countries, national PI policies have no discernible effect on firm behavior: both products are sold internationally at prices that are independent of the underlying global policy regime. This result implies that demand heterogeneity across countries is likely to be an important determinant of national PI policies. It also suggests that similarity of taste for quality can help explain why the US allows PIs of pharmaceuticals from Canada (Pecorino, 2002) or why the EU allows parallel trade among member countries.

Our analysis contributes to, and to some extent unifies, two strands of the literature on PIs: one that studies interaction between firms taking government policies as given and another that analyzes the impact of alternative government policies but abstracts from strategic interaction between firms. ${ }^{6}$ In the latter tradition, the seminal paper is by Malueg and Schwartz (1994) who show that the possibility of PIs can induce a monopolist to not serve markets with higher elasticities of demand and thereby lower world welfare. ${ }^{7}$ The central question addressed by Malueg and Schwartz is a normative one: should firms be allowed to establish exclusive sales territories internationally? Our analysis asks related questions that, in some senses, complement the normative inquiry of Malueg and Schwartz (1994). In our view, it is important to also identify the incentives that individual governments have to allow or restrict PIs from a national welfare perspective.

One of the few papers that analyzes the choice of PI policies in a multi-country setting is Richardson (2002). However, our analysis differs from his along several important dimensions. First, in our model each firm decides whether or not to sell its product in the foreign market, while Richardson (2002) considers a scenario where all countries import a common good from a

\footnotetext{
${ }^{6}$ It should be noted here that the literature on economic integration contains analyses of international oligopoly where integration or segmentation is exogenously given. See, among others, Smith and Venables (1988) and Venables (1990). Markusen and Venables (1988) examine optimal trade and industrial policy in this context. In our paper, national policies endogenously determine whether markets are segmented or integrated.

${ }^{7}$ Valletti and Szymanski (2006) build on Malueg and Schwartz (1994) by endogenising product quality and show that international exhaustion yields lower welfare relative to national exhaustion.
} 
foreign monopolist who necessarily sells in all markets. Second, by incorporating oligopolistic competition, our model captures strategic considerations absent from his analysis. Third, because each country is an importer as well as an exporter in our model, government policies must consider both consumer and producer interests, as opposed to only consumer interests. Indeed, firm profitability turns out to be an important determinant of PI policies in our model.

A commonly advanced argument against parallel trade is that it reduces innovation incentives by undermining the ability of IPR holders to profit from their investments in research and development $(\mathrm{R} \& \mathrm{D})$ - see, for instance, Li and Maskus (2006). ${ }^{8}$ In a North-South model of endogenous innovation, Grossman and Lai (2008) analyze strategic policy choice when the South determines its price control policy in response to the PI policy of the North and show that the incentives for product innovation in the North (as well as its aggregate welfare) can be higher when the North permits PIs relative to when it does not. While we focus on different questions, some of the international policy externalities identified in Grossman and Lai (2008) also appear in our analysis; in particular, Northern openness to PIs may induce the Northern firm to eschew the Southern market in order to avoid indirect competition, and this, in turn, can hurt the South.

\section{Model}

We consider a vertically differentiated industry in a world comprised of two countries: North $(N)$ and South $(S)$. The industry produces good $x$ that comes in two quality levels where $s_{h}$ denotes the high quality and $s_{l}$ the low quality $\left(s_{h}>s_{l}=1\right)$. Assume that the Northern firm produces the high quality and the Southern firm the low quality and that the cost of production for both qualities equals zero. Each consumer buys at most one unit of good $x$. If a consumer in country $i$ buys quality $j$ at price $p_{j i}$, its utility is given by

$$
U_{i}=\theta s_{j}-p_{j i} \text { where } j=h, l
$$

Utility under no purchase is normalized to zero and $\theta \geq 0$ is a taste parameter that captures the willingness to pay for higher quality. All consumers prefer high quality for a given price

\footnotetext{
${ }^{8}$ However, Valletti (2006) shows that parallel trade can actually encourage cost reducing R\&D when differential pricing is cost based.
} 
but those with a higher $\theta$ are willing to pay more for both qualities and, in addition, value high quality relatively more.

The high quality product produced by the Northern firm as well as the low quality product produced by the Southern firm are both protected by an IPR such as a patents or a trademark. In particular, it is perfectly legal for the Southern firm to sell its low quality product in both countries; the low quality product is not per se a counterfeit or illegal version of the high quality product. One can think of the two products as belonging to different generations - an existing drug and a more effective drug that is recently introduced after new scientific advances (with non-overlapping patent protection between the products); alternatively, one can think of the quality difference as reflecting country bias or perceived differences in regulatory conditions (such as monitoring of product safety), technology and input quality between the North and the South. The role of PI policy of each country is to determine whether or not the IPR enjoyed by a firm over its product is exhausted once it is sold abroad which, in turn, determines whether or not the firm can legally prevent PIs of units (of its own product) that it sells abroad. ${ }^{9}$

To capture demand asymmetry between the North and the South, we will assume that market size is larger in the North than in the South; in particular, we set the number of consumers in the South equal to 1 and in the North to $\mu \geq 1$. Further, we assume that the preference parameter $\theta$ is uniformly distributed over the interval $\left[0, \mu_{i}\right]$ in country $i=N, S$ where

$$
\mu_{N}=\mu \geq \mu_{S}=1
$$

Observe that this formulation allows us to capture asymmetry in size as well as the distribution of preferences by a single parameter $\mu$. In what follows, we refer to $\mu$ as the extent of demand heterogeneity asymmetry or between the two markets. ${ }^{10}$ Since $\mu \geq 1$, not only is the market

\footnotetext{
${ }^{9}$ Note that in our framework, if PI are permitted, consumers do not differentiate between units of the product sold directly by the manufacturing firm and those sold by an importer. This kind of differentiation may be important when the product comes with warranties and other services that are only provided by the manufacturer or it's authorized dealers. See, for instance, Ahmadi and Yang (2000).

${ }^{10}$ It should be mentioned here that the assumption that the support of $\theta$ in each market has zero as lower bound ensures that if both firms set prices without bothering about the effect of their pricing on their profit in other markets, then both sell in equilibrium. In other words, if firms choose not to serve a market in our model it is not because of the "natural monopoly" effect that can arise in models of price competition in vertically
} 
demand for both qualities higher in the North, but in fact Northern consumers exhibit higher relative preference for high quality over low quality in the sense that the distribution of $\theta$, the marginal willingness to pay for better quality, in the population of consumers in the North dominates that in the South (in a first order stochastic sense). In other words, the proportion and the number of consumers willing to pay a premium for quality is relatively higher in the North. As a result, the Northern market is more lucrative than the South for both products and relatively more so for the high quality product. Furthermore, when both products are offered for sale, demand for high quality is less price elastic in the North than in the South.

When trade is possible, the interaction between firms and governments occurs as follows. The PI policy of each government is either one of allowing PIs (denoted by $P$ ), or one of not allowing PIs (denoted by $N$ ). Thus, there exist four possible global policy regimes: $(P, P)$, $(P, N),(N, P)$, and $(N, N)$, where the policy of the North is listed first. In the next four sections, we treat the policy regimes as being exogenously given and focus on the resulting trade and market outcomes. In a later section, we analyze the problem of endogenous determination of PI policies through strategic interaction of governments.

Given national PI policies, each firm decides whether or not to offer its product for sale in the foreign market. Our implicit assumption is that each firm has the option of offering its product for sale abroad via a retail sector that is perfectly competitive in each country. ${ }^{11}$ Firms' decisions regarding the authorization of sales territories determine global market structure. In the final stage, given market structure and government policies, firms compete in prices and consumption (and trade) occur.

In our model, each firm decides whether or not to allow the sale of its product in the foreign market prior to setting prices. An important implication of this formulation is that if the high quality (Northern) firm decides not to serve the Southern market, then in the next stage, its pricing strategy in no way affects the demand for the low quality (Southern) firm's product in the South since there is no price competition between firms in the South.

${ }^{11}$ Thus, firms do not have to share rents with retailers and the vertical pricing issues that are central to the analysis of Maskus and Chen (2002) and Maskus and Chen (2004) do not arise in our model. In a related context, Raff and Schmitt (2007) have shown that when competitive retailers order inventories before observing market demand, a manufacturer can actually benefit from parallel trade.
} 
An alternative specification would be one where both products are always offered for sale in both markets and each firm simply chooses a pair of prices - one for each market. Under such a formulation, the high quality firm can effectively eliminate sales in the South by charging a price that is sufficiently higher than the price charged by the low quality firm. While equilibrium policy outcomes under this alternative approach are likely to be similar to ours, the price competition stage is more tractable under our formulation. The two approaches differ at the price competition stage because under the alternative specification an outcome where the high quality firm finds it profitable to abandon the Southern market - for instance, when PI policies prevent price discrimination and the Southern market is too small or the degree of market competition is too severe or both - could be consistent with a continuum of pricing equilibria where the high quality firm's foreign price (at which it sells zero in the South) still affects the demand curve facing the low quality firm and places a ceiling on its market power. Furthermore, these equilibria will differ with respect to the price at which Southern consumers buy the low quality good and therefore in terms of the welfare that they generate. By allowing firms to abandon foreign markets prior to price competition, our approach simplifies the price competition stage and avoids this kind of indeterminacy.

Under trade, if both qualities are available for purchase at prices $p_{h i}$ and $p_{l i}$, country $i$ 's consumers can be partitioned into three groups on the basis of two threshold parameters $\theta_{l i}$ and $\theta_{h i}$ : those in the range $\left[0, \theta_{l i}\right)$ buy neither high nor low quality; those in $\left[\theta_{l i}, \theta_{h i}\right)$ buy low quality; and those in $\left[\theta_{h i}, \mu_{i}\right]$ buy high quality where

$$
\theta_{l i}=\frac{p_{l i}}{s_{l}} \text { and } \theta_{h i}=\frac{p_{h i}-p_{l i}}{\Delta s}
$$

where $\Delta s \equiv s_{h}-s_{l}>0$. Using these threshold parameters, demand functions in country $i$ for the two qualities are as follows:

$$
x_{j i}\left(p_{l i}, p_{h i}\right)=\left\{\begin{array}{l}
\theta_{h i}-\theta_{l i}=\frac{p_{h i}-p_{l i}}{\Delta s}-\frac{p_{l i}}{s_{l}} \text { if } j=l \\
\mu_{i}-\theta_{h i}=\mu_{i}-\frac{p_{h i}-p_{l i}}{\Delta s} \text { if } j=h
\end{array}\right.
$$

The demand functions in (3) can be used to calculate consumer surplus in country $i$ over the 
two qualities:

$$
c s_{i}\left(p_{l i}, p_{h i}\right)=\sum_{j} c s_{j i}\left(p_{l i}, p_{h i}\right)=\int_{\theta_{l i}}^{\theta_{h i}}\left(s_{l} \theta-p_{l i}\right) d \theta+\int_{\theta_{h i}}^{\mu_{i}}\left(s_{h} \theta-p_{h i}\right) d \theta
$$

which simplifies to

$$
c s_{l i}\left(p_{l i}, p_{h i}\right)=\left(\theta_{h i}-\theta_{l i}\right)\left[\frac{s_{l}\left(\theta_{h i}+\theta_{l i}\right)}{2}-p_{l i}\right] \text { and } c s_{h i}=\left(\mu_{i}-\theta_{h i}\right)\left[\frac{s_{h}\left(\mu_{i}+\theta_{h i}\right)}{2}-p_{h i}\right]
$$

In what follows, let $r \equiv \frac{s_{h}}{s_{l}} \geq 1$ denote the quality gap between goods and normalize $s_{l}=1$.

\section{Alternative market outcomes}

In our model, PI policies influence global market outcomes through two channels. First, they determine whether a firm engaged in international trade can charge differential prices at home and abroad. Second, they affect a firm's incentive to authorize or not authorize sales of its product in the foreign market i.e., the decision of a firm to export or not. In this section, we briefly discuss the various market outcomes that can arise in our model. As we show later, the degree of demand asymmetry across countries $(\mu)$, the quality gap between goods $(r)$, and the PI policies of the two governments jointly determine which of these outcomes emerges in equilibrium in any given situation.

The various market outcomes can be classified as follows:

(i) Autarky $\{A\}$ : Neither firm exports so that each charges its optimal monopoly price in its home market.

(ii) International price discrimination $\{D\}$ : Both firms export and charge discriminatory prices across markets.

(iii) Uniform pricing $\{U\}$ : Both firms export and charge uniform prices at home and abroad.

(iv) Asymmetric market coverage $\{\Lambda\}$ : only the low quality firm exports and it charges the same price in both countries.

(v) Asymmetric market coverage $\left\{\Lambda^{m}\right\}$ : only the low quality firm exports but it price discriminates across countries. The superscript $m$ indicates that the low quality firm exercises full monopoly power at home (South). 
(vi) Asymmetric market coverage $H$ : only the high quality firm exports and it charges the same price in both markets.

(vii) Asymmetric market coverage $\left\{H^{m}\right\}$ : only the high quality firm exports but it charges different prices at home and abroad. The superscript $m$ indicates that the high quality firm exercises full monopoly power at home (North).

For ease of reference, the classification of market outcomes (given that at least one firm exports) is given in Table 1 below:

Table 1: Alternative market outcomes and pricing behavior

\begin{tabular}{|c|c|c|}
\hline & Differential international prices & Common international prices \\
Both firms export & $\{D\}$ & $\{U\}$ \\
Only low quality exports & $\left\{\Lambda^{m}\right\}$ & $\{\Lambda\}$ \\
Only high quality exports & $\left\{H^{m}\right\}$ & $\{H\}$ \\
\hline
\end{tabular}

Under autarky, the local firm in country $i$ acts as a monopolist. In the North, consumers in the range $\left[\theta_{h}, \mu\right]$ buy the local (high quality) good where $\theta_{h}=\frac{p_{h}}{s_{h}}$ and the demand curve facing the firm is given by $x_{h}\left(p_{h}\right)=\mu-\frac{p_{h}}{s_{h}}$. The autarkic equilibrium price in the North is the optimal monopoly price of the high quality firm:

$$
p_{h}^{m}=\frac{\mu s_{h}}{2}
$$

Similarly, in the South, the autarkic equilibrium price is the low quality firm's optimal monopoly price $p_{l}^{m}=\frac{1}{2}$.

Under price discrimination $\{D\}$, in country $i$ the low quality firm chooses $p_{l i}$ to solve

$$
\underset{p_{l i}}{\operatorname{Max}} \pi_{l i}\left(p_{l i}, p_{h i}\right)=p_{l i} x_{l i}\left(p_{l i}, p_{h i}\right)=p_{l i}\left(\frac{p_{h i}-p_{l i}}{\Delta s}-\frac{p_{l i}}{s_{l}}\right)
$$

whereas the high quality firm choose $p_{h i}$ to solve

$$
\underset{p_{h i}}{\operatorname{Max}} \pi_{h i}\left(p_{l i}, p_{h i}\right)=p_{h i} x_{h i}\left(p_{l i}, p_{h i}\right)=p_{h i}\left(\mu_{i}-\frac{p_{h i}-p_{l i}}{\Delta s}\right)
$$

The reaction functions in market $i$ under price discrimination are given by

$$
p_{l i}=\frac{p_{h i}}{2 r} \text { and } p_{h i}=\frac{\mu_{i}(r-1)}{2}+\frac{p_{l i}}{2}
$$


Under uniform pricing $\{U\}$, the low quality firm chooses $p_{l}$ to solve

$$
\underset{p_{l}}{\operatorname{Max}} \sum_{i} \pi_{l i}\left(p_{l}, p_{h}\right)=2 p_{l} x_{l}\left(p_{l}, p_{h}\right)=2 p_{l}\left(\frac{p_{h}-p_{l}}{\Delta s}-\frac{p_{l}}{s_{l}}\right)
$$

whereas the high quality firm chooses $p_{h}$ to solve:

$$
\underset{p_{h}}{\operatorname{Max}} \sum_{i} \pi_{h i}\left(p_{l}, p_{h}\right)=\sum_{i} p_{h} x_{h i}\left(p_{l}, p_{h}\right)=\sum_{i} p_{h}\left(\mu_{i}-\frac{p_{h}-p_{l}}{\Delta s}\right)
$$

The reaction functions under uniform pricing are as follows

$$
p_{l}=\frac{p_{h}}{2 r} \text { and } p_{h}=\frac{(\mu+1)(r-1)}{4}+\frac{p_{l}}{2}
$$

The reaction functions for the low quality firm are the same under discrimination and uniform pricing because the demand asymmetry parameter $\mu$ directly affects demand for only the high quality good and it does not appear in the low quality firm's first order condition for profit maximization. In other words, an increase in $\mu$ leads to an increase the low quality firm's price only because the high quality firm finds it optimal to raise its price due to an expansion in the set of Northern consumers that value quality relatively more. A comparison of the solutions to the pricing problems under $\{D\}$ and $\{U\}$ yields:

Lemma 1: Under price discrimination, each firm charges a higher price in the North: $p_{j N}(D)>p_{j S}(D)$. Furthermore, each firm's price under uniform pricing is the average of its optimal discriminatory prices in the two markets: $p_{j}(U)=\sum_{i} p_{j i}(D) / 2$.

Lemma 1 highlights an important aspect of price discrimination and uniform pricing from the viewpoint of consumer welfare. While prices are strictly lower in the North under uniform pricing relative to price discrimination, the opposite is true in the South. As we will show later, this clash between consumer welfare in the two countries over these market structures plays an important role in determining the welfare implications of different policy regimes.

While the reaction function for the low quality firm is the same under both scenarios, the reaction function for the high quality firm under uniform pricing lies above its reaction function under discrimination. As a result, the uniform pricing equilibrium in the South yields strictly higher prices than that under price discrimination. Of course, in the North, exactly the opposite situation applies. 
In our model, when both products are offered for sale in markets and firms are constrained to charge uniform prices, if there is too much asymmetry in demand for high quality between the markets then the equilibrium outcome could be one where there are no sales of the high quality good the South. To ensure that positive quantities are sold in both markets under uniform pricing, the following parameter restriction is assumed to hold through-out the paper:

Assumption 1: $\mu<\bar{\mu} \equiv \frac{6 r-1}{2 r-1}$.

In the asymmetric market outcome $\left\{\Lambda^{m}\right\}$, it is easy to see that the low quality firm charges its optimal monopoly price $p_{l}^{m}=1 / 2$ in the South and the two firms charge their optimal discriminatory prices $p_{l N}(D)$ and $p_{h N}(D)$ in the North i.e., the outcome in the Northern market is identical to that in configuration $\{D\}$.

Under $\{\Lambda\}$, the low quality firm chooses its common international price $p_{l}^{\Lambda}$ to solve

$$
\underset{p_{l}}{\operatorname{Max}} p_{l}\left(\frac{p_{h}-p_{l}}{\Delta s}-\frac{p_{l}}{s_{l}}\right)+p_{l}\left(1-\frac{p_{l}}{s_{l}}\right)
$$

where the first term denotes its profits in the North and the second in the South, where it is the sole seller. The high quality firm serves only the North and solves

$$
\underset{p_{h}}{\operatorname{Max}} p_{h}\left(\mu-\frac{p_{h}-p_{l}}{\Delta s}\right)
$$

The first order conditions for these problems yield the following reaction functions under $\{\Lambda\}$ :

$$
p_{l}=\frac{r-1}{2(2 r-1)}+\frac{p_{h}}{2(2 r-1)} \text { and } p_{h}=\frac{\mu(r-1)+p_{l}}{2}
$$

Using these reaction functions it is easy to show that the price by both low and high quality firms lie between their corresponding prices under $\{U\}$ and $\{D\}$; further, the low quality firm's price is higher than its monopoly price in the South.

Under $\{H\}$, the high quality firm chooses its common international price to solve

$$
\underset{p_{h}}{\operatorname{Max}} p_{h}\left(1-\frac{p_{h}-p_{l}}{\Delta s}\right)+p_{h}\left(\mu-\frac{p_{h}}{s_{h}}\right)
$$

whereas the low quality firm solves the same problem (in the South) as it does under international price discrimination:

$$
\underset{p_{l}}{\operatorname{Max}} p_{l}\left(\frac{p_{h}-p_{l}}{\Delta s}-\frac{p_{l}}{s_{l}}\right)
$$


Firm reaction functions under $\{H\}$ are given by

$$
p_{l}=\frac{p_{h}}{2 r} \text { and } p_{h}=\frac{r}{2 r-1}\left[\frac{(\mu+1)(r-1)}{2}+\frac{p_{l}}{2}\right]
$$

These reaction functions can be solved for equilibrium prices $p_{j}(H)$ and it is easy to show that these prices exceed those under uniform pricing: the high quality firm's desire to stay close to its optimal monopoly price in the North makes it less willing to lower its price in the South where it competes with the low quality firm. Since the low quality firm's reaction function is the same under $\{H\}$ and $\{U\}$, a less aggressive posture on the part of the high quality firm in the South also implies a higher price for the low quality firm under $\{H\}$ relative to under $\{U\}$.

Lemma 2: (i) Under the asymmetric market outcome $\{\Lambda\}$ where (only) the low quality firm serves both markets at the common international price $p_{l}(\Lambda)$, the price $p_{j}(\Lambda)$ charged by firm of quality $j, j=h, l$, lies in between its prices under $\{U\}$ and $\{D\}$ :

$$
p_{j}(U)<p_{j}(\Lambda)<p_{j N}(D), j=h, l .
$$

Furthermore, the low quality firm's price $p_{l}(\Lambda)$ exceeds its optimal monopoly price in the South.

(ii) In the asymmetric market outcome $\left\{\Lambda^{m}\right\}$ where (only) the low quality firm serves both markets, it charges its optimal monopoly price $p_{l}^{m}=1 / 2$ in the South while both firms charge their optimal discriminatory prices $p_{l N}(D)$ and $p_{h N}(D)$ in the North.

(iii) In the asymmetric market outcome $\{H\}$ where (only) the high quality firm serves both markets at the common price $p_{h}(H)$, each firm's price exceeds its price under uniform pricing: $p_{j}(U)<p_{j}(H)$ where $j=h, l$.

Having discussed the candidate market outcomes, we next consider how PI policies of individual countries influence equilibrium market outcomes. Since PIs are induced by the possibility of arbitrage between national markets, it is useful to begin with the case where PIs are permitted by the North but not by the South.

\section{If only the North permits PIs}

In this section, we derive the equilibrium market outcome under the mixed policy regime $(P, N)$ where the North permits parallel imports but the South does not. Under this policy configuration, the low quality (Southern) firm is free to compete in the Northern market at a price lower than its domestic price, the same is not true for the high quality (Northern) firm. 
We will show that this creates an incentive for the low quality firm to export i.e., serve both markets. Furthermore, if the asymmetry in demand structure between North and South is high so that the demand for high quality in the South is significantly lower than in the North, the high quality firm prefers to forsake the South and simply not export; in that case the asymmetric outcome $\{\Lambda\}$ or $\left\{\Lambda^{m}\right\}$ obtains. On the other hand, if the demand structures are not too different, the high quality firm serves both markets and we show that in that case, the North's openness to PIs is sufficient to ensure that both firms charge uniform prices i.e., market outcome $\{U\}$ obtains. In what follows, we develop the main arguments leading to these results (summarized in Proposition 2 towards the end of this section).

First, suppose that the high quality firm chooses to not serve the Southern market while the low quality firm serves both markets. Under such a scenario, the low quality firm's pricing behavior depends upon the extent of disparity in demand for high quality between the two countries. While the North's openness toward PIs undoes any attempt on its part to charge a lower price in the South, it is free to charge a higher price there since PIs are forbidden by it. Furthermore, such pricing can indeed arise when the low quality firm enjoys monopoly status in the South. To see this, suppose that the low quality firm charges its optimal monopoly price $p_{l}^{m}=1 / 2$ in the South and the two firms charge their optimal discriminatory prices $p_{l N}(D)$ and $p_{h N}(D)$ in the North. Given that only the North permits PIs, such a configuration of prices can be sustained iff

$$
p_{l S}^{m} \geq p_{l N}(D) \Leftrightarrow \frac{1}{2} \geq \frac{\mu(r-1)}{4 r-1} \Leftrightarrow \mu \leq \mu_{l}^{m} \equiv \frac{4 r-1}{2(r-1)}
$$

In other words, if $\mu \leq \mu_{l}^{m}$ the two markets in effect become perfectly segmented and despite the North's openness to PIs, the low quality firm is free to act as an unconstrained monopolist in the South. Note also that, under such a scenario, the market equilibrium in the North coincides with international price discrimination; in other words, we obtain the market outcome $\left\{\Lambda^{m}\right\}$. On the other hand, when $\mu>\mu_{l}^{m}$ the low quality firm must charge a common international price if it chooses to sell in both markets under $(P, N)$ and therefore, the asymmetric market outcome $\{\Lambda\}$ obtains. As noted in Lemma 2, under the outcome $\{\Lambda\}$, the uniform price charged by the low quality firm actually exceeds its optimal monopoly price $p_{l}^{m}=1 / 2$ in the South while it falls short of its optimal discriminatory price for the North. The inequality $p_{l}^{m}<p_{l}(\Lambda)$ holds because Northern openness to PIs induces the low quality firm to tolerate a reduction in its Southern profit in order to get closer to its preferred Northern price $p_{j N}(D)$. 
Whenever the optimal monopoly price in the South $p_{l}^{m}=1 / 2$ cannot be sustained by the low quality firm (which happens when $\mu>\mu_{l}^{m}$ ) its reaction function $R_{l}(\Lambda)$ under $\{\Lambda\}$ lies strictly above its reaction function $R_{l}(D)$ under $\{D\}$ - i.e. when $\mu>\mu_{l}^{m}$, relative to price discrimination, the low quality is relatively more aggressive in price competition. This is because $p_{l}(\Lambda)>p_{l}^{m}$ and the low quality firm is quite eager to reduce its price in response to a price cut by its rival. As a result, the equilibrium pair of prices under $\{\Lambda\}$ are lower relative to $\{D\}$ whereas they are higher relative to $\{U\}$.

It is straightforward to show that there exists $\mu_{l}^{*}$ where $\mu_{l}^{*}<\mu_{l}^{m}$ such that over the parameter range $\mu_{l}^{*}<\mu<\mu_{l}^{m}$ the low quality firm would be better off charging the common price $p_{l}(\Lambda)$ even though over this parameter range it can sustain its optimal monopoly price $p_{l}^{m}$ in the South while charging its optimal discriminatory price $p_{l N}(D)$ in the North. This is because $p_{l}(\Lambda)>p_{l N}(D)$ whenever $\mu<\mu_{l}^{m}$ : while the low quality firm would lose profit in its domestic market by charging the common international price $p_{l}(\Lambda)$, when $\mu>\mu_{l}^{*}$ this loss is more than compensated by the increase in profit that results from the softening of price competition in the Northern market. Of course, the high quality firm would necessarily benefit if the low quality firm were to charge a higher price. However, since the low quality firm cannot commit to charging a common price in both markets, when the policy regime is $(P, N)$ and $\mu \leq \mu_{l}^{m}$, in Nash equilibrium it charges different prices in the two markets: $p_{l N}(D)$ in the North and $p_{l}^{m}$ in the South.

Let $\pi_{i}(m)$ denote firm $i$ 's equilibrium profit under the market outcome $m$ and define

$$
\Delta \pi_{l} \equiv\left\{\begin{array}{c}
\pi_{l}\left(\Lambda^{m}\right)-\pi_{l}(A) \text { for } \mu \leq \mu_{l}^{m} \\
\pi_{l}(\Lambda)-\pi_{l}(A) \text { for } \mu>\mu_{l}^{m}
\end{array}\right\}
$$

as the low quality firm's unilateral incentive to serve the North - i.e. $\Delta \pi_{l}$ is the incremental profit earned by the low quality firm from serving the North given that the high quality firm does not serve the Southern market.

Our first result is as follows:

Proposition 1: If the North permits PIs whereas the South does not, the autarkic market outcome $\{A\}$ cannot arise in equilibrium since the low quality firm's unilateral incentive to serve the Northern market is strictly positive: i.e. $\Delta \pi_{l}>0$ for all feasible $\mu$ and $r$.

To see why this is true, suppose the policy regime is $(P, N)$ and $\mu \leq \mu_{l}^{m}$. When $\mu \leq \mu_{l}^{m}$, if the low quality firm serves the North the market outcome $\left\{\Lambda^{m}\right\}$ obtains i.e., it can earn 
optimal monopoly profit at home (equal to that under autarky) earn an incremental profit of $\pi_{l N}(D)$ from the foreign market. Even though $p_{l}^{m} \geq p_{l S}(D)$, PIs cannot flow to the South due to its policy stance. Thus, when the Northern demand is only moderately higher than its own market - i.e. $\mu \leq \mu_{l}^{m}$ - the low quality firm is able to sustain its optimal monopoly price in the South when local policy prevents PIs from flowing in. As a result, $\Delta \pi_{l}(\Lambda)>0$.

Now suppose $\mu>\mu_{l}^{m}$. Under this scenario, the pricing behavior described in part $(i)$ of Lemma 2 applies and in the appendix we show that $\Delta \pi_{l}=\pi_{l}(\Lambda)-\pi_{l}(A)>0$. The intuition is as follows: when $\mu>\mu_{l}^{m}$, preserving its monopoly status in the much smaller Southern market is not particularly attractive to the low quality firm. Indeed, as noted earlier, for $\mu>\mu_{l}^{m}$ the low quality firm is willing to charge a price above its optimal monopoly price in the South so as to serve the North at a more desirable price.

Consider next the high quality firm's unilateral incentive to serve the South under $(P, N)$. Given that the low quality firm does not serve the North and the North permits PIs, the high quality firm can charge its optimal monopoly price in the North while competing with the low quality firm in the South iff

$$
p_{h}^{m} \leq p_{h S}(D) \Leftrightarrow \frac{\mu r}{2} \leq \frac{2 r(r-1)}{4 r-1} \Leftrightarrow \mu \leq \mu_{h}^{m} \equiv \frac{4(r-1)}{4 r-1}
$$

i.e. $\mu_{h}^{m}$ is the critical threshold below which the high quality firm's optimal monopoly price in the North lies below its optimal discriminatory price in the smaller one. Observe, however, that $\mu_{h}^{m}<1$ for all $r>1$ and since $\mu \geq 1$, it follows that it is impossible for the high quality firm to sustain its optimal monopoly price in the North when its government permits PIs and firms compete only in the South. Thus, under $(P, N)$, the high quality firm necessarily charges a common international price when it is the only firm that exports and therefore, the asymmetric market outcome $\{H\}$ obtains.

Let the high quality firm's unilateral incentive to serve the South be defined by

$$
\Delta \pi_{h} \equiv \pi_{h}(H)-\pi_{h}(A)
$$

The following result is intuitive:

Lemma 3: When the North permits PIs and the South does not, the high quality firm's unilateral incentive for serving the South $\Delta \pi_{h}$ decreases in $\mu$. Furthermore, $\Delta \pi_{h} \geq 0$ iff $\mu \leq \mu_{h}$ where $\frac{d \mu_{h}}{d r}>0$. 
To derive the equilibrium market outcome, we next consider each firm's best response when the rival firm chooses to serve both markets. Suppose that the high quality firm chooses to serve the South. If the low quality firm opts to serve the North in response, the uniform pricing outcome $\{U\}$ obtains due to the North's openness to PIs. If it does not, outcome $\{H\}$ obtains under which the high quality is sold in both markets at the common international price $p_{h}(H)$. Given this, the low quality firm's reciprocal incentive for serving the North when it must charge a common price in both markets (due to the North's openness to PIs) is defined by

$$
\Delta \pi_{l}(U) \equiv \pi_{l}(U)-\pi_{l}(H)
$$

It is straightforward to show that $\Delta \pi_{l}(U) \geq 0$ iff $r \geq r^{*}=1+\frac{3 \sqrt{2}}{8} .{ }^{12}$

In what follows, we assume that the degree of product differentiation is not so low that the low quality firm has no reciprocal incentive to serve the Northern market when it permits PIs. In other words, we assume the following:

Assumption 2: Let $r \geq r^{*} \Longleftrightarrow \Delta \pi_{l}(U) \geq 0$.

This assumption has two important implications. First, it ensures that there exists a unique equilibrium market structure and outcome for all feasible parameter values and policy combinations. Second, it implies that outcome $\{H\}$ cannot be an equilibrium outcome.

Consider now the high quality firm's best response to the low quality firm serving the Northern market. Given that the low quality product is sold in both markets, if the high quality firm chooses to serve both markets uniform pricing obtains under $(P, N)$. On the other hand, if the high quality firm decides to not serve the Southern market the resulting market outcome depends upon the degree of North-South size asymmetry: when $\mu \leq \mu_{l}^{m}$ we obtain $\left\{\Lambda^{m}\right\}$ whereas for $\mu>\mu_{l}^{m}$, we get $\{\Lambda\}$. Given this, the high quality firm's reciprocal incentive is defined as follows:

$$
\Delta \pi_{h}(U) \equiv\left\{\begin{array}{c}
\pi_{h}(U)-\pi_{h N}(D) \text { for } \mu \leq \mu_{l}^{m} \\
\pi_{h}(U)-\pi_{h}(\Lambda) \text { for } \mu>\mu_{l}^{m}
\end{array}\right\}
$$

\footnotetext{
${ }^{12}$ Note that the demand disparity between countries does not determine whether or not the low quality firm has a reciprocal incentive to serve the North. Intuitively, when the high quality firm serves both markets under $(P, N)$, prices in each market depend upon $\mu$ even if the low quality firm does not serve the North. As a result, $\mu$ does not determine whether or not $\Delta \pi_{l}(U)>0$ even though $\Delta \pi_{l}(U)$ is strictly increasing in $\mu$ over the range over which it is positive.
} 
It is straightforward to show that for $\mu \leq \mu_{l}^{m}$

$$
\Delta \pi_{h}(U) \geq 0 \Leftrightarrow \mu \leq \mu^{*} \equiv 1+\sqrt{2}
$$

whereas for $\mu>\mu_{l}^{m}$ we have

$$
\Delta \pi_{h}(U) \geq 0 \Leftrightarrow \mu \leq \mu^{u}
$$

where $\mu^{u} \leq \mu^{*}$ iff $\mu \leq \mu_{l}^{m} ; \lim _{r \rightarrow \infty} \mu^{u}=\mu^{*}$; and $\mu_{h}<\mu^{u}$. The fact that the high quality firm's reciprocal incentive is positive only when the Northern demand for high quality is not too large relative to the South is quite intuitive: given that the North permits PIs, the larger the Northern demand for high quality relative to the South, the more constrained is the high quality firm's pricing behavior in the North.

Using the two types of incentive functions (unilateral and reciprocal), we can derive market outcomes under the policy pair $(P, N)$. These outcomes are illustrated in Figure 1 drawn in the $(r, \mu)$ space.

- Figure 1 here -

The downward sloping curve $\mu_{l}^{m}$ in Figure 1 defines the boundary below which the low quality firm is able to charge its optimal monopoly price $p_{l}^{m}$ in the South so that the market outcome $\left\{\Lambda^{m}\right\}$ is relevant whereas above $\mu_{l}^{m}$, the low quality firm charges the price $p_{l}(\Lambda)$ in both markets and the market outcome $\{\Lambda\}$ is relevant.

The horizontal line plots $\mu=\mu^{*}$ : below this curve the high quality firm has a reciprocal incentive to serve the South when the low quality firm is able to sustain its optimal monopoly price (i.e. it plots $\Delta \pi_{h}(U) \geq 0$ for $\left.\mu \leq \mu_{l}^{m}\right)$. Above $\mu^{*}$, the high quality firm lacks such an incentive and prefers the market outcome $\left\{\Lambda^{m}\right\}$ to uniform pricing $\{U\}$. The outer upward sloping curve $\mu_{h}^{U}$ in Figure 1 plots the locus of $\Delta \pi_{h}(U)=0$ below which the high quality firm has a reciprocal incentive to serve the South when the low quality firm charges the common international price $p_{l}(\Lambda)$ under $\{\Lambda\}$ (i.e. for $\mu>\mu_{l}^{m}$ ). Below the lower upward sloping curve $\mu_{h}$, the high quality firm has a unilateral incentive to serve the South given that $\mu \leq \mu_{l}^{m}$.

When the demand asymmetry between the two countries exceeds the outer boundary defined by $\mu^{u}$ and $\mu^{*}$ - i.e. in region $\boldsymbol{C}$ where $\mu^{*}<\mu \leq \mu_{l}^{m}$ and in region $\boldsymbol{D}$ where $\mu>$ $\max \left\{\mu_{l}^{m}, \mu^{u}\right\}$ - the high quality firm prefers to not serve the South and the equilibrium market 
outcome is determined by the low quality firm's pricing behavior: in region $\boldsymbol{C}$ the equilibrium outcome is $\left\{\Lambda^{m}\right\}$ whereas in region $\boldsymbol{D}$ it is $\{\Lambda\}$. It is worth emphasizing that the decision to not serve the South on the part of the high quality firm reflects considerations that come into play solely due to the North's policy of permitting PIs since, by assumption, selling abroad imposes no additional costs on firms. On the other hand, below the outer boundary defined by $\mu^{u}$ and $\mu^{*}$ (i.e. over region $\boldsymbol{A}$ where $\mu \leq \mu^{u}$ and region $\boldsymbol{B}$ where $\mu^{u} \leq \mu \leq \mu^{*}$ ), markets are fairly similar in demand structure and the equilibrium market outcome is uniform pricing.

We close this section by summarizing the main results in Proposition 2:

Proposition 2: If the North permits PIs and the South does not, the equilibrium market outcomes are as follows:

(i) uniform pricing obtains when $\mu \leq \max \left\{\mu^{u}, \mu^{*}\right\}$ (regions $\boldsymbol{A}$ and $\boldsymbol{B}$ in Figure 1);

(ii) the asymmetric outcome $\left\{\Lambda^{m}\right\}$ obtains when $\mu^{*}<\mu \leq \mu_{l}^{m}$ (region $\boldsymbol{C}$ in Figure 1); and

(iii) the asymmetric outcome $\{\Lambda\}$ obtains when $\mu>\max \left\{\mu_{l}^{m}, \mu^{u}\right\}$ (region $\boldsymbol{D}$ in Figure $1)$.

\section{If both countries permit}

In this section, we derive the equilibrium market outcome under the policy pair $(P, P)$ i.e. when both countries permit PIs. We begin by observing that $(P, P)$, regardless of the degree of market asymmetry, if a firm serves both markets it must do so at a common international price. More specifically, this implies that market outcomes $\left\{\Lambda^{m}\right\}$ and $\{D\}$ cannot arise.

Next, we argue that Proposition 1 does not hold under $(P, P)$ : i.e., when both countries permit PIs, the low quality firm does not necessarily have a unilateral incentive to serve the North. Intuitively, when products are not highly differentiated, the decision to serve the North is not attractive to the low quality firm because price competition in the North is fierce. And since the low quality firm must charge a common price in both markets under $(P, P)$, stringent competition in the North also undermines its profit in the Southern market. ${ }^{13}$ Under $(P, P)$, direct calculations show that

$$
\Delta \pi_{l} \geq 0 \Leftrightarrow \mu \geq \mu_{l}^{\Lambda}
$$

\footnotetext{
${ }^{13}$ By contrast, under $(P, N)$ the low quality firm's profit in the Southern market is relatively better protected due to the Southern prohibition on PIs and it therefore necessarily has a unilateral incentive to serve the North. Recall that when $\mu \leq \mu_{l}^{m}$, the low quality firm actually earns monopoly profit in its market under $(P, N)$ if the high quality firm chooses to not sell its good there.
} 
Uniform pricing is an equilibrium under $(P, P)$ iff each firm has a reciprocal incentive to serve the foreign market: i.e. $\Delta \pi_{j}(U) \geq 0$ for $j=h, l$. Using the incentive functions $\Delta \pi_{j}(U)$ along with $\Delta \pi_{h}$ and $\Delta \pi_{l}$ allows us to fully describe equilibrium market outcomes under $(P, P)$.

Figure 2 illustrates equilibrium market structures under $(P, P)$.

- Figure 2 here -

Consider first the low quality firm's incentives. Above the downward sloping curve $\Delta \pi_{l}=0$ or $\left(\mu=\mu_{l}^{\Lambda}\right)$ the low quality firm has a unilateral incentive to serve the foreign market. The negative slope of the curve is intuitive: as the intensity of product market competition decreases (i.e. $r$ increases), the critical level of Northern demand required to induce the low quality firm to sell in the North declines.

The high quality firm's unilateral incentive to serve the Southern market $\Delta \pi_{h}$ as well as its reciprocal incentive $\Delta \pi_{h}(U)$ both decrease with $\mu .{ }^{14}$ This is because the larger the demand disparity between countries, the more important it is for the firm to charge a higher price in the North. Indeed, in so far as the unilateral incentive is concerned, the high quality firm is evaluating whether or not to preserve its optimal monopoly price in the North under autarky relative to serving both markets at $p_{h}(H)$ where $p_{h}(H)<p_{h}^{m}$.

It is useful to compare Figures 1 and 2. The first point to note is that in region $\boldsymbol{D}$ (i.e. when $\left.\mu>\max \left\{\mu_{l}^{m}, \mu^{u}\right\}\right)$, the equilibrium outcome under both $(P, P)$ and $(P, N)$ is $\{\Lambda\}$. When the low quality firm cannot sustain its optimal monopoly price in the South under $(P, N)$, the North's permissive policy towards PIs is the main determinant of market outcome: the high quality firm chooses not to serve the South in order to stay close to its preferred price for the Northern market.

Second, in region $\boldsymbol{C}$ (where $\mu^{*}<\mu \leq \mu_{l}^{m}$ ) while $\{\Lambda\}$ obtains when both countries permit PIs, $\left\{\Lambda^{m}\right\}$ obtains when only the North does so. Recall from Lemma 2 that under $\left\{\Lambda^{m}\right\}$ prices in the North equal $p_{j N}(D)$ while in the South the low quality firm charges its optimal monopoly price $p_{l}^{m}=1 / 2$. Thus, given that the North permits PIs and the South does not, when $\mu \leq \mu_{l}^{m}$ the Southern firm is less aggressive during price competition under the asymmetric outcome $\{\Lambda\}$ relative to that under $\left\{\Lambda^{m}\right\}: p_{l}(\Lambda)>p_{l}^{m}$ and $p_{j N}(D)>p_{j}(\Lambda)$. Thus, as we emphasize in Proposition 3 below, over region $\boldsymbol{C}$ prices are higher in the North when both countries permit

\footnotetext{
${ }^{14}$ Assumption 2 guarantees that the low quality firm has a reciprocal incentive to serve the North under $(P, P)$.
} 
PIs relative to when only the North does so while the opposite is true of prices in the South. As a result, given that the North permits PIs and the Northern firm does serve the South, the firm's profit is higher in region $\boldsymbol{C}$ if the South permits PIs relative to when it does not. Thus, the presence of strategic competition implies that, holding the Northern PI policy constant, a unilateral reversal of Southern policy (from banning PIs to allowing them) can increase the Northern firm's profit by softening price competition in the Northern market.

Third, while rough intuition suggests that uniform pricing might be more likely to obtain when both countries permit PIs relative to when only the North does, a comparison of Figures 1 and 2 show that this is not the case. More specifically, note from these figures that over region $\boldsymbol{A}$ uniform pricing obtains under both $(P, P)$ and $(P, N)$ whereas over region $\boldsymbol{B}$ uniform pricing obtains only under $(P, N)$. Over region $\boldsymbol{B}$, the high quality firm's preference between alternative markets outcomes is as follows: $\{\Lambda\} \succ\{U\} \succ\left\{\Lambda^{m}\right\}$. Over this region, when only the North permit PIs, the high quality firm ends up serving the South since it prefers uniform pricing $\{U\}$ to $\left\{\Lambda^{m}\right\}$. However, when both countries permit PIs $\left\{\Lambda^{m}\right\}$ is not feasible since the low quality firm must charge a common international price that exceeds its optimal discriminatory price for the North. The softening of price competition in the Northern market over region $\boldsymbol{B}$ under $\{\Lambda\}$ makes it worthwhile for the high quality firm to not serve the South under $(P, P)$. It is noteworthy that it is the inability of its rival to price discriminate internationally under the regime $(P, P)$ relative to $(P, N)$ that makes the high quality firm opt for the asymmetric outcome $\{\Lambda\}$ over uniform pricing.

We collect the main results of this section below:

Proposition 3: Suppose both countries permit PIs. Then, uniform pricing obtains when $\mu \leq \mu^{u}$ (region $\boldsymbol{A}$ in Figure 1 ) and the asymmetric market outcome $\{\Lambda\}$ obtains otherwise. ${ }^{15}$ For a subset of the parameter space where the degree of asymmetry between markets is in an intermediate range (i.e. over region $\boldsymbol{C}$ in Figure 1 where $\mu^{*}<\mu \leq \mu_{l}^{m}$ ), prices are actually higher in the North when both countries permit PIs compared to the policy regime $(P, N)$ where only the North permits PIs.

\footnotetext{
${ }^{15}$ For completeness, we should note that there is a tiny area over which both autarky and uniform pricing are equilibria. This area is defined by $\mu_{h} \leq \mu \leq \mu_{l}^{\Lambda}$. In this area, each firm has a reciprocal incentive to serve the foreign market but no unilateral incentive to do so. For the remainder of the paper, we will take uniform pricing to be the equilibrium over this tiny region.
} 


\section{If North forbids}

In this section, we discuss the equilibrium market outcomes when the North forbids parallel imports. We begin by deriving the equilibrium market outcome under the policy regime $(N, P)$ where the South permits PIs.

We first argue that the autarkic outcome cannot be an equilibrium when the North prohibits PIs since the high quality firm has a unilateral incentive to serve the South. To see why, suppose the low quality firm does not serve the North. Then, the high quality firm charges its optimal monopoly price in the North so long as the South's permissive policy towards PIs does not prevent it from doing so. In this regard, recall that $\mu_{h}^{m}$ is the critical threshold above which the high quality firm's optimal monopoly price in the North exceeds its optimal discriminatory price in the South and that $\mu_{h}^{m} \leq 1$ for all $r \geq 1$. But since $\mu \geq 1 \geq \mu_{h}^{m}$, it follows that the high quality can always sustain its optimal monopoly price in the North when the Northern government forbids PIs and firms compete (only) in the South. This implies that beginning at autarky, under $(N, P)$ the high quality firm will necessarily choose to serve the South. Doing so brings an incremental gain of $\pi_{h S}(D)$ while protecting its monopoly profit in the North: PIs are prohibited by the North and no PIs occur to the South since the price of the high quality good is lower there $\left(p_{h}^{m} \geq p_{h S}(D)\right)$.

We now argue that the low quality firm necessarily has a reciprocal incentive to serve the North when it forbids PIs. To see this simply note that by deviating from $\{H\}$ to $\{D\}$ the low quality firm secures an incremental gain of $\pi_{l N}(D)$ without having any detrimental affect on its monopoly profit in the South. This implies that the market structure $\{H\}$ cannot be an equilibrium under $(N, P)$.

Next, observe that when the North forbids PIs, the Northern policy makes it possible for the high quality firm to price discriminate internationally. This observation rules out uniform pricing as an equilibrium outcome. Thus, there remain only three candidates for equilibrium under $(N, P):\{\Lambda\},\left\{\Lambda^{m}\right\}$, and $\{D\}$.

As before, the choice between two of three remaining candidates for equilibrium outcomes $-\{\Lambda\}$ and $\left\{\Lambda^{m}\right\}$ - is determined by the the degree of demand asymmetry. When the South is open to PIs and the North is not, the low quality firm can charge its optimal monopoly price in the South only when that price is lower than its discriminatory price in the North: i.e. $p_{l S}^{m} \leq p_{l N}(D) \Leftrightarrow \mu \geq \mu_{l}^{m}$. Thus, over $\mu \geq \mu_{l}^{m}$, the equilibrium has to be either $\left\{\Lambda^{m}\right\}$ 
or $\{D\}$. However, $\left\{\Lambda^{m}\right\}$ fails to be an equilibrium because the high quality firm necessarily has a reciprocal incentive to serve the South when $\mu \geq \mu_{l}^{m}$ : by serving the South it secures an incremental gain of $\pi_{h S}(D)$ in the South without lowering its profit $\pi_{h N}(D)$ in the North. Thus, we have shown that when $\mu \geq \mu_{l}^{m}$, both firms have a reciprocal incentive to serve the foreign market and international price discrimination $\{D\}$ is the equilibrium outcome.

Now consider the case $\mu<\mu_{l}^{m}$. Consider $\{\Lambda\}$ as a candidate for equilibrium over this parameter range. Starting at $\{\Lambda\}$ if the high quality firm chooses to serve the South, we move to market outcome $\{D\}$ whereas if the low quality firm chooses to withdraw from the North we revert to autarky $\{A\}$. This implies that $\{\Lambda\}$ is an equilibrium iff $(i) \pi_{h}(D)<\pi_{h}(\Lambda) \Leftrightarrow \mu>$ $\mu_{h}^{d}$ and $(i i) \pi_{l}(\Lambda)>\pi_{l}(A) \Leftrightarrow \mu>\mu_{l}^{\Lambda}$. It is easy to show that the curve $\mu_{h}^{d}$ lies strictly to the left of $r^{*}$ so that Assumption 2 rules out the parameter range $\mu_{l}^{\Lambda} \leq \mu<\mu_{h}^{d}$. In other words, since $r>r^{*}$ it must be that $\Delta \pi_{h}(D)>0$.

Thus, we have argued that both types of incentives - unilateral as well as reciprocal - are positive for both firms under the policy pair $(N, P)$. This necessarily implies that international price discrimination is the unique equilibrium outcome under $(N, P)$.

Finally, it is transparent that if the policy pair is $(N, N)$ and PIs cannot flow in either direction, it is a dominant strategy for each firm to serve the foreign market. Furthermore, absent the threat of PIs, firms will charge their optimal discriminatory prices in each market.

We have:

Proposition 4: If the North forbids PIs, the Southern policy is inconsequential and international price discrimination obtains as the equilibrium outcome.

It is worth noting that Proposition 4 does not imply that both firms are better off under international price discrimination relative to autarky. In fact, it is easy to see that both can be worse off relative to autarky when the degree of product differentiation $(r)$ is relatively low: under such circumstances severe price competition lowers their respective profits below autarkic levels. This is shown in Figure 3 which plots the zero-profit contours for $\Delta \pi_{j}(D) \equiv$ $\pi_{j}(D)-\pi_{j}(A)$. The downward sloping contour is that of the low quality firm while the upward sloping one is for the high quality firm.

- Figure 3 here -

Figure 3 can be divided into four regions. In region $\boldsymbol{\delta}$, the degree of demand asymmetry $(\mu)$ is moderate and products are highly differentiated ( $r$ is large) and both firms are better 
off relative to autarky: each firm gets access to another market that is comparable in demand to its local market where such access is accompanied by price competition that is relatively weak. By contrast, in region $\boldsymbol{\alpha}$, the severity of price competition under international price discrimination tips the balance in favor of autarky for both firms. In region $\boldsymbol{\beta}$, only the high quality firm is better off under international price discrimination while in region $\gamma$ only the low quality firm is better off. The intuition is as follows. In region $\gamma$, the North-South demand asymmetry is large and the low quality firm benefits substantially from being able to sell its good in the North whereas the high quality firm has to share its large domestic market with a competitor and therefore loses relative to autarky. Finally, in region $\boldsymbol{\beta}$, demand asymmetry is small and product differentiation is moderately large: under such a scenario, sharing its local market in return for access to the comparably sized Southern market is not as costly for the high quality firm since its competitor is at a substantial quality disadvantage. For analogous reasons, in region $\boldsymbol{\beta}$ the low quality firm is better off under autarky relative to international price discrimination.

\section{Equilibrium government policies}

We are now ready to derive equilibrium policies. Each country's objective is to maximize its welfare. Country $i$ 's welfare under market outcome $\{M\}$ is a weighted sum of consumer surplus and firm profits:

$$
w_{i}(M)=\lambda \sum_{j} c s_{j i}(m)+(1-\lambda)\left(\pi_{d i}(M)+\pi_{e i}(M)\right)
$$

where $M=A, D, H, \Lambda, \Lambda^{m}$ or $U$ and $0 \leq \lambda \leq 1$. In the above welfare function, $\pi_{d i}(M)$ denotes profit of country $i$ 's firm in its domestic market whereas $\pi_{e i}(M)$ denotes its export profit. Also, let world welfare under market outcome $\{M\}$ be given by $w w(M)=w_{N}(M)+w_{S}(M)$.

In what follows, we focus primarily on the case where government's maximize aggregate welfare (i.e. $\lambda=1 / 2$ ) and then comment briefly on the two polar cases where governments care only about firms or consumers.

\subsection{Welfare maximizing governments $(\lambda=1 / 2)$}

Our first welfare result reports a comparison of the different market outcomes from the viewpoint of each country: 
Proposition 5: Suppose governments seek to maximize national welfare (i.e. $\lambda=1 / 2$ ). Then, each country's welfare ranking of the various market outcomes that can arise in equilibrium is as follows:

(i) For the North: $w_{N}(U)>w_{N}(D)>w_{N}(\Lambda)>w_{N}\left(\Lambda^{m}\right)$ whereas

(ii) for the South: $w_{S}(D)>\max \left\{w_{S}(U), w_{S}(\Lambda), w_{S}\left(\Lambda^{m}\right)\right\}$.

Note in particular that the welfare of the North under uniform pricing is strictly higher than that under international price discrimination whereas the welfare of the South is strictly lower. From the South's perspective, price discrimination is preferred to uniform pricing due to two reasons. First, its firm enjoys strictly higher export profits under discrimination since price competition in the North is softer relative to uniform pricing. Second, recall from Lemma 2 that relative to uniform pricing, prices are lower in the South under price discrimination. As a result, both firm profitability and consumer welfare considerations work in the same direction for the South. However, as Proposition 4 notes, whether or not price discrimination obtains in equilibrium depends on North's PI policy and not on that of the South.

For the North, consumer welfare and firm profitability work against each other: while consumers are better off under uniform pricing, the high quality firm prefers discrimination. Since higher prices under discrimination transfer part of the Northern consumer surplus over to the low quality firm in terms of profits, the North's aggregate welfare is higher under uniform pricing relative to international price discrimination.

We are now in a position to consider each country's optimal PI policy in response to the other. Suppose South permits PIs. What is North's optimal PI policy? We can answer this question using Figure 1 and Proposition 5. First note from Proposition 5 that the North will permit PIs so long as parameters are such that its firm exports to the South when both markets allow PIs. Using Figure 1, we conclude that, given that the South permits PI, the North adopts the same PI policy iff $\mu \leq \mu^{u}$ i.e. over region $\boldsymbol{A}$ where the Northern firm's reciprocal incentive is positive. Now suppose the South bans PIs. Then, Figure 1 implies that the North will permit PIs over both regions $\boldsymbol{A}$ and $\boldsymbol{B}$ (i.e. iff $\mu \leq \max \left\{\mu^{*}, \mu^{u}\right\}$ ) since the high quality firm's reciprocal incentive to export is positive over these regions under policy pair $(N, P)$. Thus, over region $\boldsymbol{B}$ the North permits PIs only when the South forbids them implying that Southern openness to PIs reduces North's willingness to permit PIs.

Now consider the South's best response to the North's policy choice. Recall that a ban on PIs by the North makes the South indifferent between its policy options since the ban 
is sufficient to induce international price discrimination. But what if the North permits PIs? Then, Figures 1 and 2 indicate that Southern policy matters only over region $\boldsymbol{B}\left(\mu^{u} \leq \mu \leq \mu^{*}\right)$ and region $\boldsymbol{C}\left(\mu^{u}<\mu^{*} \leq \mu\right)$. Over the rest of the parameter space, Northern openness to PIs determines the market outcome and the South is indifferent between its two policy options.

Over region $\boldsymbol{B}$, given that North permits PIs, South prefers to permit PIs in order to obtain the asymmetric market outcome $\{\Lambda\}$ as opposed to uniform pricing while over region $\boldsymbol{C}$, it prefers to permit PIs to obtain $\{\Lambda\}$ as opposed to $\left\{\Lambda^{m}\right\}$ since $w_{S}(\Lambda) \geq w_{S}\left(\Lambda^{m}\right)$ iff $\mu \leq \mu_{l}^{m}$. Thus, given that the North allows PI, the South strictly prefers to allow PIs over regions $\boldsymbol{B}$ and $\boldsymbol{C}$ whereas it is indifferent between its two policy options otherwise.

To derive equilibrium policies, suppose we are in region $\boldsymbol{A}$ (i.e. $\mu \leq \mu^{u}$ ) so that the high quality firm's reciprocal incentive is positive when the low quality firm charges a common international price in both markets. It is easy to see that both $(P, N)$ and $(P, P)$ are Nash equilibria over region $\boldsymbol{A}$ : the North has no incentive to deviate since uniform pricing is its most preferred regime whereas the South's PI policy is inconsequential for the market outcome.

Now consider region $\boldsymbol{B}$ (i.e. when $\left.\mu^{u} \leq \mu \leq \mu^{*}\right)$. Here the market equilibrium under $(P, P)$ is $\{\Lambda\}$ whereas under $(N, P)$ it is international price discrimination. Since $w_{N}(D) \geq w_{N}(\Lambda)$ the North bans PIs in region $\boldsymbol{B}$ to ensure international price discrimination obtains thereby making Southern policy inconsequential. Thus, in region $\boldsymbol{B}$, both $(N, P)$ and $(N, N)$ are Nash equilibria. Similarly, in region $\boldsymbol{C}$ (i.e. when $\mu^{u}<\mu^{*} \leq \mu$ ) and region $\boldsymbol{D}$, i.e. for $\mu>\max \left\{\mu^{u}\right.$, $\left.\mu_{l}^{m}\right\}$, it is optimal for the North to forbid PIs to induce international price discrimination and avoid the asymmetric outcome $\{\Lambda\}$ while the Southern policy is inconsequential.

We can now state:

Proposition 6: When governments maximize national welfare (i.e. $\lambda=1 / 2$ ) the equilibrium market outcome is determined by the North's PI policy:

(i) For $\mu \leq \mu^{u}$ (region $\boldsymbol{A}$ in Figure 1) i.e., when the degree of asymmetry between demand structures of the two countries is not too large, permitting PIs is a dominant policy choice for the North and uniform pricing obtains independent of the South's PI policy. ${ }^{16}$ In particular, $(P, P)$ and $(P, N)$ are both Nash equilibria.

(ii) For $\mu>\mu^{u}$ (regions $\boldsymbol{B}, \boldsymbol{C}$, and $\boldsymbol{D}$ in Figure 1) i.e., when the degree of asymmetry between demand structures of the two markets is large, prohibiting PIs is a strictly dominant policy choice for the North and international price discrimination obtains, independent of the PI policy of the South. In particular, policy pairs $(N, P)$ and $(N, N)$ are both Nash equilibria.

\footnotetext{
${ }^{16}$ If the inequality is strict - i.e. $\mu<\mu^{u}-$ then it is a strictly dominant strategy for the North to permit PIs.
} 
(iii) The PI policy of the South is always inconsequential in equilibrium.

When markets are sufficiently asymmetric in their demand structure, the North forbids PIs to rule out asymmetric market outcomes $\left\{\Lambda^{m}\right\}$ and $\{\Lambda\}$ under which its own firm chooses to not serve the South so as to charge a high price in the North, which is detrimental for Northern consumers and overall Northern welfare. Note also that the nature of the North's equilibrium policy is such that the Southern policy has no effect on market outcomes, and therefore, welfare. This policy outcome is quite consistent with the observed variation of PI policies across the world. As we noted earlier, the two largest markets in the world - EU and the USA - restrict PIs from the rest of the world while there is substantial variation among developing countries with respect to their PI policies, an outcome that might be indicative of the fact that no one type of PI policy is strictly preferable from their viewpoint.

To gain further insight into the welfare calculus underlying North's decision to ban PIs over all regions except region $\boldsymbol{A}$, suppose the policy pair is $(P, N)$ and the Northern firm chooses to not export. Now consider a reversal in North's policy from permitting PIs to banning them. The first point to note is that in region $\boldsymbol{C}$, this unilateral change in Northern policy has no effect on prices in the Northern market since under the asymmetric outcome $\left\{\Lambda^{m}\right\}$, market prices in the North coincides with price discrimination (see Lemma 2). Thus, over region $\boldsymbol{C}$, forbidding PIs increases Northern welfare because it yields additional export profits without having any adverse effect on local consumer surplus.

Over region $\boldsymbol{D}$, if the North chooses to ban PIs in order to induce its firm to export, there are two conflicting effects on Northern welfare. On the positive side, the export profit earned by the high quality firm contributes to Northern welfare. On the negative side, prices in the North are higher under $\{D\}$ relative to $\{\Lambda\}$. However, since prices of both firms increase and it is the change in the reaction function of the Southern firm that causes equilibrium prices to change, it turns out that the share of Northern consumers buying the high quality actually increases. To see this, note that under international price discrimination we have

$$
\theta_{l N}(D)=\frac{\mu(r-1)}{4 r-1} \text { and } \theta_{h N}(D)=\frac{\mu(2 r-1)}{4 r-1}
$$

whereas under the asymmetric outcome $\{\Lambda\}$ we have

$$
\theta_{l N}(\Lambda)=\frac{(\mu+2)(r-1)}{8 r-5} \text { and } \theta_{h N}(\Lambda)=\frac{4 \mu r-3 \mu-1}{8 r-5}
$$


It is straightforward to calculate that

$$
\theta_{l N}(D)<\theta_{l N}(\Lambda) \text { iff } \mu>\mu_{l}^{m} \text { and } \theta_{h N}(D)>\theta_{h N}(\Lambda) \text { iff } \mu>\mu_{l}^{m}
$$

In other words, since $\mu>\mu_{l}^{m}$ in region $\boldsymbol{D}$ while market coverage (i.e. the total number of consumers buying either good) is lower in the North under price discrimination relative to the asymmetric outcome $\{\Lambda\}$, a higher proportion of them buy the high quality good. This switching by consumers from low to high quality dampens the adverse effect of the price increases that result when the North changes its policy from allowing PIs to banning them thereby altering the market outcome from $\{\Lambda\}$ to $\{D\} .{ }^{17}$

Finally, note that in region $\boldsymbol{B}$, the North has no unilateral incentive deviate from $(P, N)$ to $(N, N)$ since uniform pricing obtains under $(P, N)$ whereas price discrimination obtains under $(N, N)$. However, in region $\boldsymbol{B}$, if the North were to permits PIs, the South also prefers to permit PIs to induce the outcome $\{\Lambda\}$. But since $w_{N}(D)>w_{N}(\Lambda)$ and a Northern ban on PIs is sufficient to yield international price discrimination, in equilibrium, the North ends up banning PIs to avoid $\{\Lambda\}$.

It is also noteworthy that when the North does ban PIs, its PI policy generates a substantial positive spillover for the South: not only do Southern consumers enjoy low prices under discrimination, the low quality firm also benefits from being able to charge a more attractive price in the North.

It is easy to show that aggregate world welfare is strictly higher under uniform pricing relative to price discrimination: $w w(U)>w w(D)>\max \left\{w w(\Lambda), w w\left(\Lambda^{m}\right)\right\} .{ }^{18}$ Intuitively, by yielding price differentials across countries, international price discrimination creates an inefficiency relative to uniform pricing. The two symmetric market outcomes dominate the asymmetric ones because the latter involve less competition in the Southern market. Proposition 6 shows that when countries are not too different in demand structure (as is the case over region $\boldsymbol{A}$ ), even though each is guided purely by its own interest, equilibrium policies are efficient in that they maximize aggregate welfare.

\footnotetext{
${ }^{17}$ An analogous logic explains why the North finds it optimal to ban PIs over all regions other than $\mathbf{A}$ when the South permits PIs and its firm decides not to export. As is clear, Southern policy is irrelevant for explaining why the North forbids PIs over region $\mathbf{D}$ since the outcome $\{\Lambda\}$ obtains regardless. However, over regions $\mathbf{B}$ and $\mathbf{C}$ the PI policy of the South does matter since the outcome $\left\{\Lambda^{m}\right\}$ cannot arise when the South is open to PIs. To understand why the North deviates from $(P, P)$ to $(N, P)$ over regions $\mathbf{B}$ and $\mathbf{C}$ where $\mu \leq \mu_{l}^{m}$, note that this change in Northern policy causes local consumers to switch from high to low quality but this switching is offset by the fact that total market coverage expands - i.e. fewer consumers abstain from buying either good.

${ }^{18}$ Indeed, we can show that $w_{S}(\Lambda)+w_{N}(\Lambda) \geq w_{S}\left(\Lambda^{m}\right)+w_{N}\left(\Lambda^{m}\right)$ iff $\mu \leq \mu_{l}^{m}$.
} 
What if government policies were chosen not to maximize aggregate welfare? We turn to this next.

\subsection{If $\lambda \neq 1 / 2$}

Consider the case where $\lambda=0$ i.e. governments care only about firm profits. To derive equilibrium policies, simply recall that a unilateral prohibition of PIs by the North is sufficient to ensure price discrimination, the most preferred market structure of its firm. As a result, when $\lambda=0$ the policy outcome is as described by part (ii) of Proposition 6 .

Now consider the situation where governments care only about consumers (i.e. $\lambda=1$ ). First consider South's best response to alternative Northern policies. As before, a Northern ban on PIs delivers South's most preferred outcome and its policy becomes irrelevant. If the North is open to PIs, Southern policy matters only when the high quality firm's reciprocal incentive is negative (i.e. it matters in all regions other than region $\boldsymbol{A}$ where $\mu^{*} \leq \mu^{u}$ ). Over region $\boldsymbol{B}$, given that the North permits PI, it is optimal for South to ban PIs because doing so leads to uniform pricing under which prices are lower in the South relative to the market outcome $\{\Lambda\}$. Over region $\boldsymbol{C}$, the South prefers to allow PIs because doing so yields the market outcome $\{\Lambda\}$ which is preferable to $\left\{\Lambda^{m}\right\}$ since $C S_{S}(\Lambda) \geq C S_{S}\left(\Lambda^{m}\right)$ whenever $\mu \leq \mu_{l}^{m}$. Finally, for $\mu>\max \left\{\mu_{l}^{m}, \mu^{u}\right\}$, the Southern policy is irrelevant since the equilibrium outcome $\{\Lambda\}$ is invariant to its policy. Thus, if the North permits PIs, the South prefers to ban PIs over regions $\boldsymbol{B}$, permit them over region $\boldsymbol{C}$, and it is indifferent otherwise whereas if the North forbids PI, the South is indifferent between its two policy options.

Recall that the prices in the North under $\left\{\Lambda^{m}\right\}$ is the same as that international price discrimination so that we have $C S_{N}(D)=C S_{N}\left(\Lambda^{m}\right)$. Part $(i)$ of Lemma 2 implies that $C S_{N}(U)>\max \left\{C S_{N}(D), C S_{N}(\Lambda)\right\}$. Furthermore, $C S_{N}(D) \geq C S_{N}(\Lambda)$ iff $\mu \leq \mu_{l}^{m}$ since the low quality firm's common international price $p_{j}(\Lambda)$ is higher than its optimal discriminatory price $p_{j N}(D)$ in the Northern market iff $\mu \leq \mu_{l}^{m}$.

Suppose the South permits PI and consider the North's best response. It is clear that in region $\boldsymbol{A}$ (i.e. for $\mu \leq \mu^{u}$ ) it is optimal for the North to permit PIs in order to induce uniform pricing. However, over other regions uniform pricing is not an equilibrium under $(P, P)$ and the best the North can do is induce the market outcome it prefers between $\{D\}$ and $\{\Lambda\}$. Since $C S_{N}(D) \geq C S_{N}(\Lambda)$ iff $\mu \leq \mu_{l}^{m}$, if the South permits PIs, the North forbids them in regions $\boldsymbol{B}$ and $\boldsymbol{C}$ to induce international price discrimination whereas it permits them in region $\boldsymbol{D}$ to 
induce the outcome $\{\Lambda\}$.

Consider now the scenario where South forbids PI. What is North's best response? As before, in region $\boldsymbol{A}$ it is optimal for the North to permit PIs to induce uniform pricing. In addition, the North permits PIs also over region $\boldsymbol{B}$ (i.e. when $\mu^{u} \leq \mu \leq \mu^{*}$ ) since doing so results in uniform pricing (see Figure 1). In region $\boldsymbol{C}$ (i.e. when $\mu^{u} \leq \mu^{*} \leq \mu$ ) the North is indifferent between permitting and not permitting PIs since $C S_{N}(D)=C S_{N}\left(\Lambda^{m}\right)$. Finally, in region $\boldsymbol{D}$ i.e. when $\mu>\max \left\{\mu_{l}^{m}, \mu^{u}\right\}$ Northern consumer welfare is higher if it permits PIs since doing so yields the market outcome $\{\Lambda\}$ and $C S_{N}(\Lambda) \geq C S_{N}(D)$ when $\mu \geq \mu_{l}^{m}$. Thus, when $\lambda=1$, given that the South forbids PIs, the North (weakly) prefers to allow PIs: over region $\boldsymbol{C}$ it is indifferent between its policy options whereas everywhere else it strictly prefers to allow PIs.

We can now state the following result:

Proposition 7: If governments care only about consumer surplus (i.e. $\lambda=1$ ), the following hold in equilibrium:

(i) Over region $\boldsymbol{A}$ and $\boldsymbol{D}$ i.e., when demand asymmetry is relatively small or very large, permitting PIs is a dominant strategy for the North and the policy choice of the South is inconsequential; both $(P, N)$ and $(P, P)$ are Nash equilibria. Uniform pricing is the resulting market outcome in region $\boldsymbol{A}$ while the asymmetric market outcome $\{\Lambda\}$ obtains in region $\boldsymbol{D}$.

(ii) Over region $\boldsymbol{B}$, the policy Nash equilibrium is $(P, N)$ and uniform pricing obtains.

(iii) Over region $\boldsymbol{C}$, prohibiting PIs is a dominant strategy for the North and the policy choice of the South is inconsequential; both $(N, P)$ and $(N, N)$ are Nash equilibria with international price discrimination as the market outcome.

Two things are worth noting about Proposition 7 . First, when governments care only about consumer welfare, equilibrium PI policies are such that international price discrimination is less likely to arise as an equilibrium outcome since the North has a strong incentive to keep local prices low by keeping its market open to PI. Second, in region $\boldsymbol{D}$, North chooses to open its market to PIs to induce the asymmetric outcome $\{\Lambda\}$ under which prices are lower in the North relative to international price discrimination. By contrast, recall from Proposition 6 that only symmetric market outcomes obtain when governments weigh consumer and firm interests equally. 


\subsection{Discussion of the model}

In order to make the study of strategic interaction at two different stages (policy setting and the product market) tractable, we made several simplifying assumptions. In this section, we briefly discuss how our results would be affected if these assumptions were dropped.

For simplicity, like the existing literature on PI, we assume that authorizing products for sale in foreign markets does not impose any additional costs (marginal or fixed) on firms. An important advantage of this approach is that it allows us to highlight the interaction between PI policies, pricing behavior, and the strategic incentives firms have for selling or not selling in each other's markets even when such sales do not involve additional costs relative to domestic sales. In particular, in our model, whenever the Northern firm chooses to not serve the South it does so not to economize on costs but rather to increase profits by being able to charge a high price in the North.

We expect that the qualitative nature of our results should continue to hold if firms were to face additional fixed costs for accessing foreign markets so long as these costs are small relative to product market profits. To see why, suppose firms incurred a fixed cost for selling abroad. If so, each of incentive functions plotted in Figures 1 and 2 would shift so as to reduce the parameter space over which the two types of incentives (unilateral and reciprocal) are positive. For example, in Figure 1 both the $\mu_{h}$ and $\mu^{u}$ curves shift downwards when firms incur a fixed cost for selling abroad. While these shifts in the two curves would alter the parameter space over which each of the market structures is an equilibrium, it would not change the range of outcomes described in Figures 1 and 2 provided that the costs of selling abroad are not so large so as to completely eliminate the incentive to do so under some (or all) of the policy regimes. As is clear, the key welfare rankings from the perspective of the two regions also would not be affected by the presence of such costs. For example, the North would still prefer uniform pricing to price discrimination while the South would have the opposite preferences. Of course, the existence of these costs would reduce each firm's export profit which in turn would imply that the Northern government would be less concerned about inducing its firm to export. Note, however, that in our model the firm's incentive to export is always weaker than that what is socially optimal for its home economy. Thus, it would still be the case that the firm would choose not to export even when its better for its home economy that it do so. This implies that the nature of the policy equilibrium would also be similar to that in our model. ${ }^{19}$

\footnotetext{
${ }^{19}$ Note also that a similar argument applies to the case where firms incur higher marginal costs for exporting,
} 
Our model also takes product quality to be exogenously given. While endogenzing quality is beyond the scope of this paper, it is worth discussing how we expect our analysis to be modified when quality is endogenously determined. Since what matters in the model is the relative quality level of the two firms, fix the Southern firm's quality at 1 and suppose the Northern firm's quality is determined by its investment in quality improvement. Following Valleti (2006), one would expect the firm's incentive to improve quality would be stronger when it can price discriminate internationally relative to when it cannot. This implies that the Northern government's preference for uniform pricing could be reduced if the Northern firm's incentive to improve quality is substantially higher under international price discrimination. If so, our key policy result (i.e. Proposition 6) would need to be modified in the sense that uniform pricing would likely be preferred by the North over a smaller parameter space in order to increase its firm's incentive to improve quality. In our view, further research is necessary to formally verify this intuitive conjecture, particularly when both firms can invest in quality improvement as opposed to just the Northern firm. Indeed, given that the existing literature on the impact of PI policies on R\&D has tended to focus almost exclusively on monopoly, our model could serve as a foundation for further research in the area.

\section{Concluding remarks}

A sizeable literature analyzes the pros and cons of parallel trade (see Maskus, 2000 for a comprehensive overview). However, this literature has shed only limited light on factors that determine national PI policies. In this paper, we endogenize PI policies in a North-South duopoly model where the Northern firm produces the high quality and the Southern firm the low quality. A crucial feature of the model is that, given government policies, each firm decides whether or not to offer its product for the sale in the foreign market. Incorporating this feature into the model allows us to endogenously derive asymmetric market structures of the type where both qualities are sold in the North while only the low quality is sold in the South. Not only are such market structures interesting with respect to the pricing behavior of firms, the possibility that they can arise under certain North-South policy configurations plays a crucial role in determining equilibrium policies.

say due to the existence of tariffs or trade costs: under such a scenario each firm's export profit would shrink, but the Northern government would still be interested in inducing its firm to export. This in turn implies that the qualitative nature of our key policy conclusions should hold even if the marginal cost of exports were to exceed that for domestic sales. 
Intuition suggests that the Northern policy stance ought to play a key role in determining international market structure. This intuition finds support in our model, but we show that heterogeneity in demand structure across countries can matter in rather unexpected ways. In this regard, our key result - and one that matches quite well with the observed nature of real world national PI policies - is that if the Northern demand and, more particularly, preference for high quality is sufficiently higher than that of the South, the North forbids PIs and international price discrimination obtains as the equilibrium outcome. An especially noteworthy aspect of this result is that international price discrimination is the South's most preferred market structure; the North's welfare is actually higher under uniform pricing. Of course, in choosing to forbid PIs, the North is motivated not by altruism but rather its own interests: a ban on PIs by the North prevents a scenario where its own (high quality) firm abstains from serving the Southern market in order to shore up its profit at home. Thus, when demand heterogeneity across markets is high, by preventing indirect competition from arbitrage-induced PIs, the Northern prohibition on PIs induces direct competition in both markets. Only when markets are relatively similar in demand structure does the North choose to permit PIs and obtain its most preferred market outcome - i.e. uniform pricing - as an equilibrium outcome.

Our analysis of PI policies is novel in that it allows for oligopolistic competition in the product market. In our view, this is important in the context of parallel trade: while market power is pervasive when firms are protected by patents or other IPRs, true monopolies are rather rare. For example, even in the context of pharmaceuticals several competing firms often supply drugs and medicines that help treat any given illness or disease. Secondly, in our model, government policy takes into account both consumer and firm interests. As noted above, while setting its PI policy, the North must account for the possibility that its own firm might forsake the Southern market in order to sustain a more attractive price in its local market. By contrast, in the existing literature, PI policies have been studied primarily from the viewpoint of importing countries.

While the model provides some new insights, it abstracts from several important aspects of parallel trade that deserve further research. For example, it remains to be seen what additional considerations arise under oligopoly when one explicitly takes into account the role of intermediaries in parallel trade and the problems of vertical control or contracting as analyzed by Maskus and Chen (2002 and 2004). It would also be worthwhile to study 
the two-way relationship between parallel trade and strategic R\&D competition, particularly in terms of investments in quality improvement. Finally, our analysis considers PI policies in isolation, ignoring conventional instruments of trade policy such as tariffs and quotas. It would be useful to analyze a model in which PI policies are determined jointly with such trade policy instruments in order to obtain a better understanding of any potential linkages between these types of policies. We hope future research will address some of these topics.

\section{Appendix}

\section{Proof of Lemma 1}

Under international price discrimination, equilibrium prices in country $i$ are:

$$
p_{l i}(D)=\frac{\mu_{i}(r-1)}{4 r-1} \text { and } p_{h i}(D)=2 r p_{l i}(D)
$$

Equilibrium prices under uniform pricing are

$$
p_{l}(U)=\frac{(r-1)(\mu+1)}{2(4 r-1)} \text { and } p_{h}(U)=2 r p_{l}(U)
$$

Note from (15) and (16) that under uniform pricing each firm charges the average of its optimal discriminatory prices:

$$
2 p_{j}(U)=\sum_{i} p_{j i}(D)
$$

\section{Proof of Lemma 2}

Using the reaction functions reported in the text, prices under uniform pricing are given by

$$
p_{h}(U)=\frac{(\mu+1)(r-1) r}{4 r-1} \text { and } p_{l}(U)=\frac{p_{l}(U)}{2 r}
$$

Firm reaction functions under $\{\Lambda\}$ are given by

$$
p_{l}=\frac{p_{h}+(r-1)}{2(2 r-1)} \text { and } p_{h}=\frac{\mu(r-1)+p_{l}}{2}
$$

which yield the following equilibrium prices

$$
p_{l}(\Lambda)=\frac{(\mu+2)(r-1)}{(8 r-5)} \text { and } p_{h}(\Lambda)=\frac{(r-1)(2 \mu(2 r-1)+1)}{(8 r-5)}
$$

with associated profits $\pi_{j}(\Lambda)$. Since $r \geq 1$ it is straightforward that the low quality firm's common price in both markets under $\{\Lambda\}$ is higher than its price under uniform pricing:

$$
p_{l}(\Lambda)-p_{l}(U)=\frac{(r-1)}{2} \frac{8 r+3 \mu+1}{(4 r-1)(8 r-5)}>0
$$


Firm reaction functions under $\{H\}$ are given by

$$
p_{l}=\frac{p_{h}}{2 r} \text { and } p_{h}=\frac{r}{2 r-1}\left[\frac{(\mu+1)(r-1)}{2}+\frac{p_{l}}{2}\right]
$$

which yield the following equilibrium prices

$$
p_{h}(H)=\frac{2(r-1)(\mu+1) r}{(8 r-5)} \text { and } p_{l}(H)=\frac{p_{h}^{H}}{2 r}
$$

Finally, we have

$$
p_{h}(H)-p_{h}(U)=\frac{3 r(\mu+1)(r-1)}{(4 r-1)(8 r-5)}>0
$$

which also implies that $p_{l}(H)>p_{l}(U)$.

\section{Proof of Lemma 3}

One can derive the profits $\pi_{j}(H), j=H, L$ using (23). Directly solving $\Delta \pi_{h}(H)=0$ for $\mu$ yields $\mu_{h}^{H}(r)$. While the analytical expression for $\mu_{h}^{H}(r)$ is tedious, differentiating it with respect to $r$ yields the last statement of Lemma 3.

\section{Proof of Proposition 1}

The proof proceeds in a straightforward way. Directly calculations show that $\Delta_{l}(\Lambda) \equiv$ $\pi_{l}(\Lambda)-\pi_{l}(A)$ is increasing in $\mu$ and that $\Delta_{l}(\Lambda)>0$ at $\mu=\mu_{l}^{m}$. This implies that $\Delta_{l}(\Lambda)>0$ for all $\mu>\mu_{l}^{m}$. As argued in the paper, when $\mu \leq \mu_{l}^{m}$, the low quality firm faces no trade-off in its local market and serving the North yields a strictly positive gain.

\section{Other supporting calculations}

Equilibrium firm profits under uniform pricing equal

$$
\pi_{l}(U)=\frac{r(r-1)(\mu+1)^{2}}{2(4 r-1)^{2}} \text { and } \pi_{h}(U)=4 r \pi_{l}(U)
$$

whereas under international price discrimination we have

$$
\pi_{l S}(D)=\frac{(r-1) r}{(4 r-1)^{2}} \text { whereas } \pi_{l N}(D)=\frac{\mu^{2}(r-1) r}{(4 r-1)^{2}}
$$

which implies

$$
\pi_{l}(D) \equiv \sum_{i} \pi_{l i}(D)=\frac{\left(\mu^{2}+1\right)(r-1) r}{(4 r-1)^{2}}
$$

Similarly,

$$
\pi_{h}(D) \equiv \sum_{i} \pi_{h i}(D)=4 r \pi_{l}(D)
$$




\section{Proof of Proposition 5}

Let $\lambda=1 / 2$. Directly calculating aggregate Northern welfare under uniform pricing and price discrimination and subtracting yields

$$
w_{N}(U)-w_{N}(D)=\frac{r(4 r+1)(r-1)(\mu+3)(\mu-1)}{16(4 r-1)^{2}} \geq 0
$$

Furthermore, note that

$$
w_{N}(D)-w_{N}\left(\Lambda^{m}\right)=\frac{\pi_{h N}(D)}{2}=\frac{2 r^{2} \mu^{2}(r-1)}{(4 r-1)^{2}}>0
$$

which implies

$$
w_{N}(U)>w_{N}(D)>w_{N}\left(\Lambda^{m}\right)
$$

The inequality $w_{N}(D)>w_{N}(\Lambda)$ can be shown as follows. First, we have

$$
\frac{d\left(w_{N}(D)-w_{N}(\Lambda)\right)}{d \mu}=-\frac{2(r-1)^{3}\left(\mu-\mu_{l}^{m}\right)}{(4 r-1)(8 r-5)^{2}}>0 \text { iff } \mu \leq \mu_{l}^{m}
$$

Furthermore, direct calculations show that at $\mu=1$ we have $w_{N}(D)>w_{N}(\Lambda)$. Thus, it must be that $w_{N}(D)>w_{N}(\Lambda)$ whenever $\mu \leq \mu_{l}^{m}$. Now consider the case when $\mu>\mu_{l}^{m}$ so that the welfare difference $w_{N}(D)-w_{N}(\Lambda)$ is decreasing in North-South demand asymmetry $\mu$. Direct calculations show that at the maximum permissible value of $\mu$, i.e. at $\mu=\bar{\mu}$, we have $w_{N}(D)>w_{N}(\Lambda)$. Thus, it must be that $w_{N}(D)>w_{N}(\Lambda)$ for all $\mu$.

Now consider Southern welfare. We have

$$
w_{S}(D)-w_{S}(U)=\frac{r(r-1)(7 \mu-4 \mu r+20 r-3)(\mu-1)}{16(4 r-1)^{2}} \geq 0 \text { since } \mu \leq \bar{\mu}
$$

Next, we have

$$
w_{S}(D)-w_{S}\left(\Lambda^{m}\right)=\frac{4 r(r-1)+3}{16(4 r-1)}>0
$$

Thus, we have

$$
w_{S}(D)>w_{S}(U)>w_{S}\left(\Lambda^{m}\right)
$$

The inequality $w_{S}(D)>w_{S}(\Lambda)$ can be shown as follows. We have

$$
\left.\frac{\partial\left(w_{S}(D)-w_{S}(\Lambda)\right)}{\partial \mu}\right|_{\mu=\mu_{l}^{m}}=\frac{(4 r+1)(r-1)}{4(4 r-1)(8 r-5)}>0
$$

i.e. at the lowest value of $\mu$ that is relevant for comparing $w_{S}(D)$ and $w_{S}(\Lambda)$, the welfare difference $w_{S}(D)-w_{S}(\Lambda)$ is increasing in $\mu$. Furthermore, we have

$$
\frac{\partial^{2}\left(w_{S}(D)-w_{S}(\Lambda)\right)}{\partial^{2} \mu}=\frac{3(r-1)^{2}\left(16 r^{2}-8 r-1\right)}{2(4 r-1)^{2}(8 r-5)^{2}}>0
$$


which implies that $\frac{\partial\left(w_{S}(D)-w_{S}(\Lambda)\right)}{\partial \mu}>0$ for all $\mu \geq \mu_{l}^{m}$. Since we know that at $\mu=\mu_{l}^{m}$ we have

$$
w_{S}(D)-w_{S}(\Lambda)=w_{S}(D)-w_{S}\left(\Lambda^{m}\right)=\frac{4 r(r-1)+3}{16(4 r-1)}>0
$$

it must be that $w_{S}(D)>w_{S}(\Lambda)$ for for all $\mu \geq \mu_{l}^{m}$.

\section{References}

[1] Ahmadi, R., Yang, B.R., 2000. Parallel imports: Challenges from unauthorized distribution channels. Marketing Science 19, 279-94.

[2] Danzon, P. and A. Epstein, 2008. Effects of regulation on drug launch and pricing in interdependent markets. National Bureau of Economic Research Working Paper No. 14041.

[3] Danzon, Patricia, Wang, Y. Richard and L. Wang, 2005. The impact of price regulation on the launch delay of new drugs. Journal of Health Economics 14, 269-92.

[4] Gansland, Mattias and Keith E. Maskus, 2004. Parallel imports and the pricing of pharmaceutical products: Evidence from the European Union. Journal of Health Economics 23, 1035-1057.

[5] Goldberg, P. K., 2009. Intellectual property rights protection in developing countries: the case of pharmaceuticals. Journal of the European Economic Association, forthcoming.

[6] Grossman, G.M., Lai, E., 2008. Parallel imports and price controls. Rand Journal of Economics 39, 378-402.

[7] Kanavos, P., Costa-i-Font, J., Merkur, S., Gemmill, M., 2004. The economic impact of pharmaceutical parallel trade in European member states: a stakeholder analysis. Special Research Paper, LSE Health and Social Care, London School of Economics and Political Science.

[8] Lanjouw, J. O., 2005. Patents, price controls and access to new drugs: how policy affects global market entry. National Bureau of Economic Research Working Paper No. 11321.

[9] Li, C., Maskus, K.E., 2006. The impact of parallel imports on investment in cost-reducing research and development. Journal of International Economics 68, 443-455.

[10] Malueg, D.A., Schwartz, M., 1994. Parallel imports, demand dispersion, and international price discrimination. Journal of International Economics 37, 167-195.

[11] Markusen, J.R., Venables, A.J., 1988. Trade policy with increasing returns and imperfect competition. Journal of International Economics 24, 299-316. 
[12] Maskus, K.E., 2000. Parallel imports. World economy 23, 1269-1284.

[13] Maskus, K.E., Chen, Y., 2002. Parallel imports in a model of vertical distribution: theory, evidence, and policy. Pacific Economic Review 7, 319-334.

[14] Maskus, K.E., Chen, Y., 2004. Vertical price control and parallel imports: theory and evidence. Review of International Economics 12, 551-570.

[15] Pecorino, P. , 2002. Should the US allow prescription drug reimports from Canada? Journal of Health Economics 21, 699-708.

[16] Raff, H., Schmitt, N., 2007. Why parallel trade may raise producers' profits. Journal of International Economics 71, 434-447.

[17] Richardson, M., 2002. An elementary proposition concerning parallel imports. Journal of International Economics 56, 233-245.

[18] Scherer, F., Watal, J., 2002. Post-TRIPS options for access to patented medicines in developing nations. Journal of International Economic Law 5, 913-939.

[19] Shaked, A., Sutton, J., 1983. Natural oligopolies. Econometrica 51, 1469-84.

[20] Smith, A., Venables, A.J., 1988. Completing the internal market in the European Community: Some industry simulations. European Economic Review 32, 1501-1525.

[21] Valleti, T.M., 2006. Differential pricing, parallel trade, and the incentive to invest. Journal of International Economics 70, 314-324.

[22] Valletti, T.M., Szymanski, S., 2006. Parallel trade, international exhaustion and intellectual property rights: a welfare analysis. Journal of Industrial Economics 54, 499-526.

[23] Venables, A.J., 1990. The economic integration of oligopolistic markets. European Economic Review 34, 753-73. 


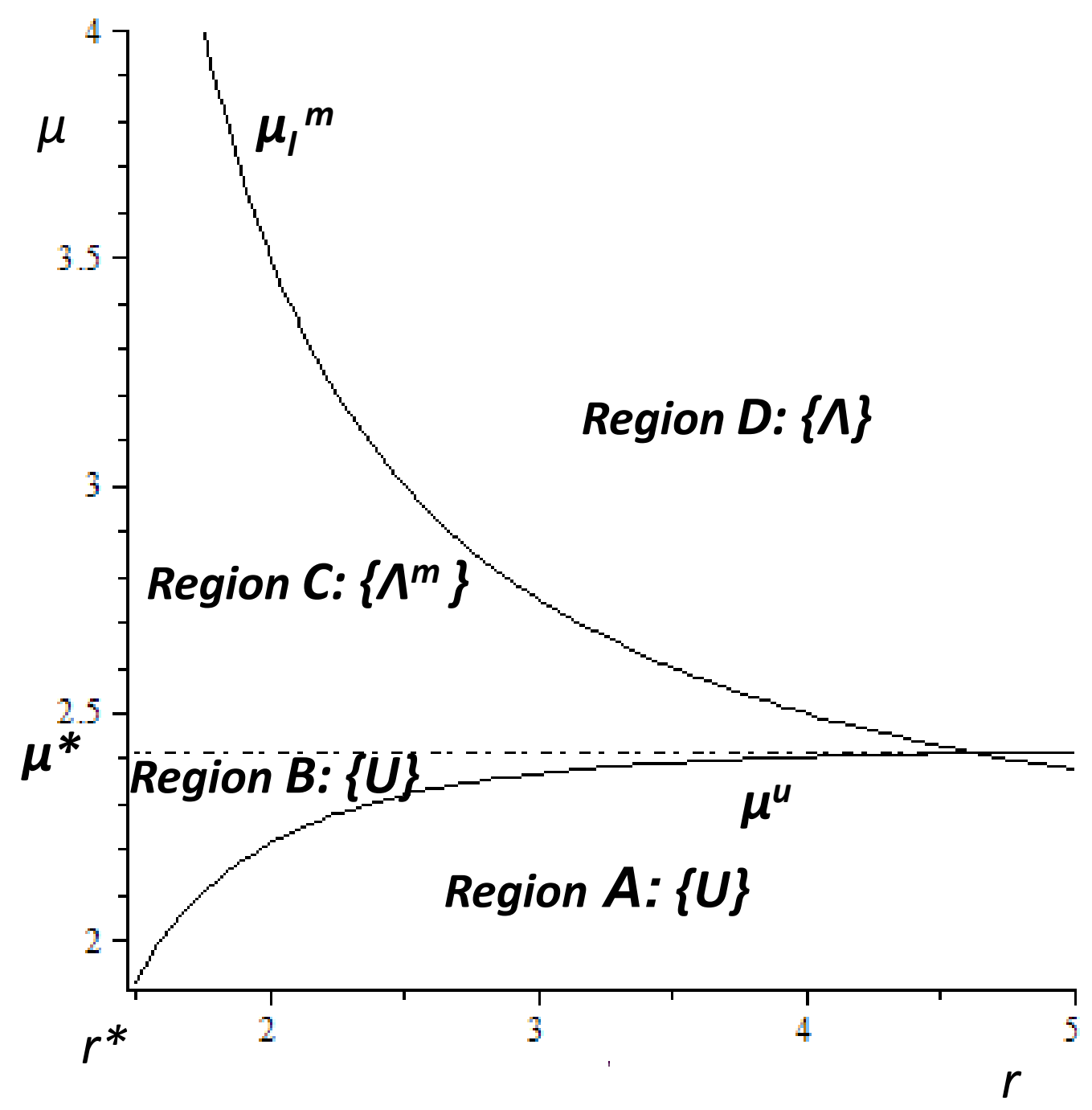

Figure 1: Equilibrium market structure under $(P, N)$ 


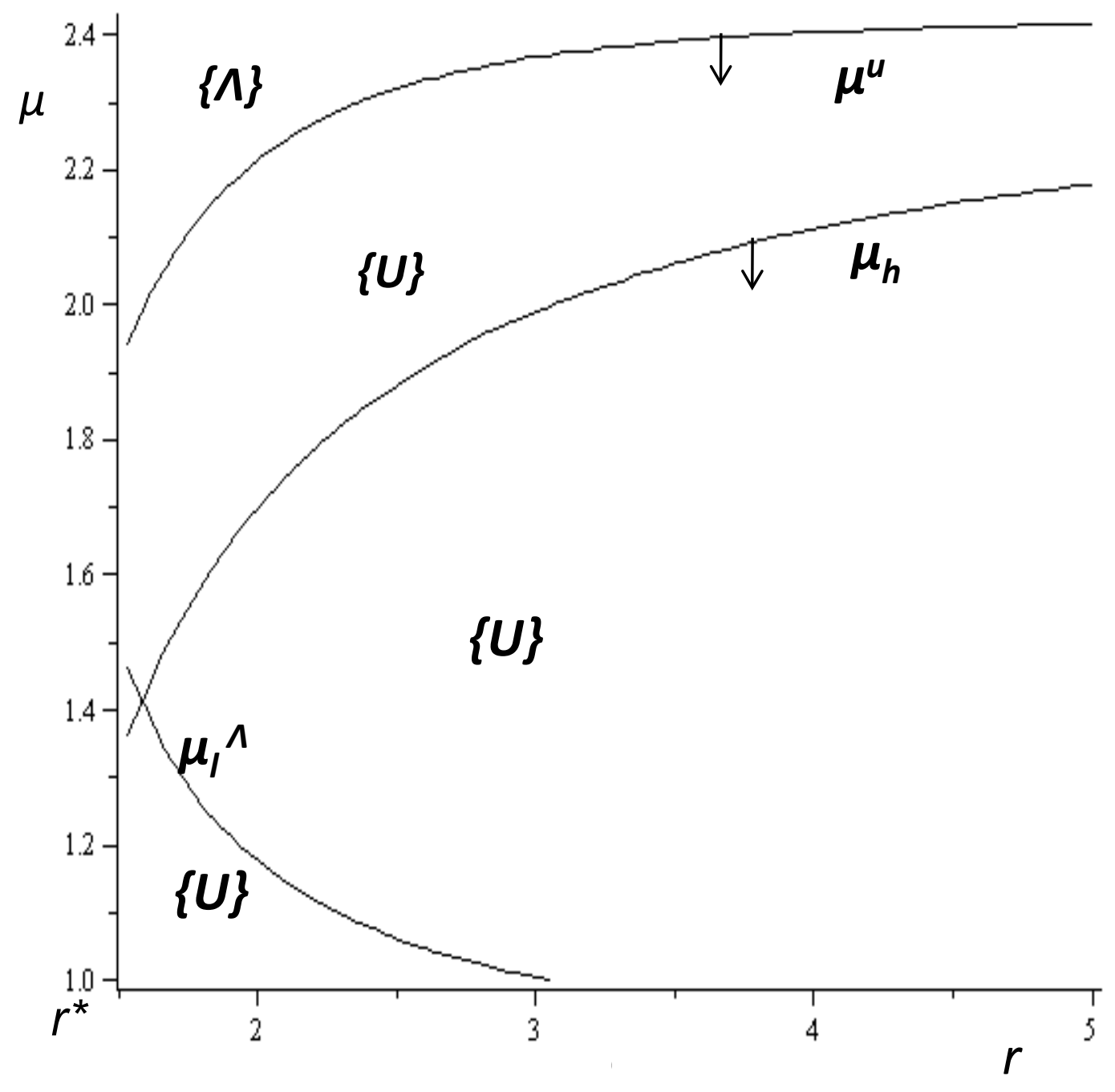

Figure 2: Equilibrium market structure under $(P, P)$ 


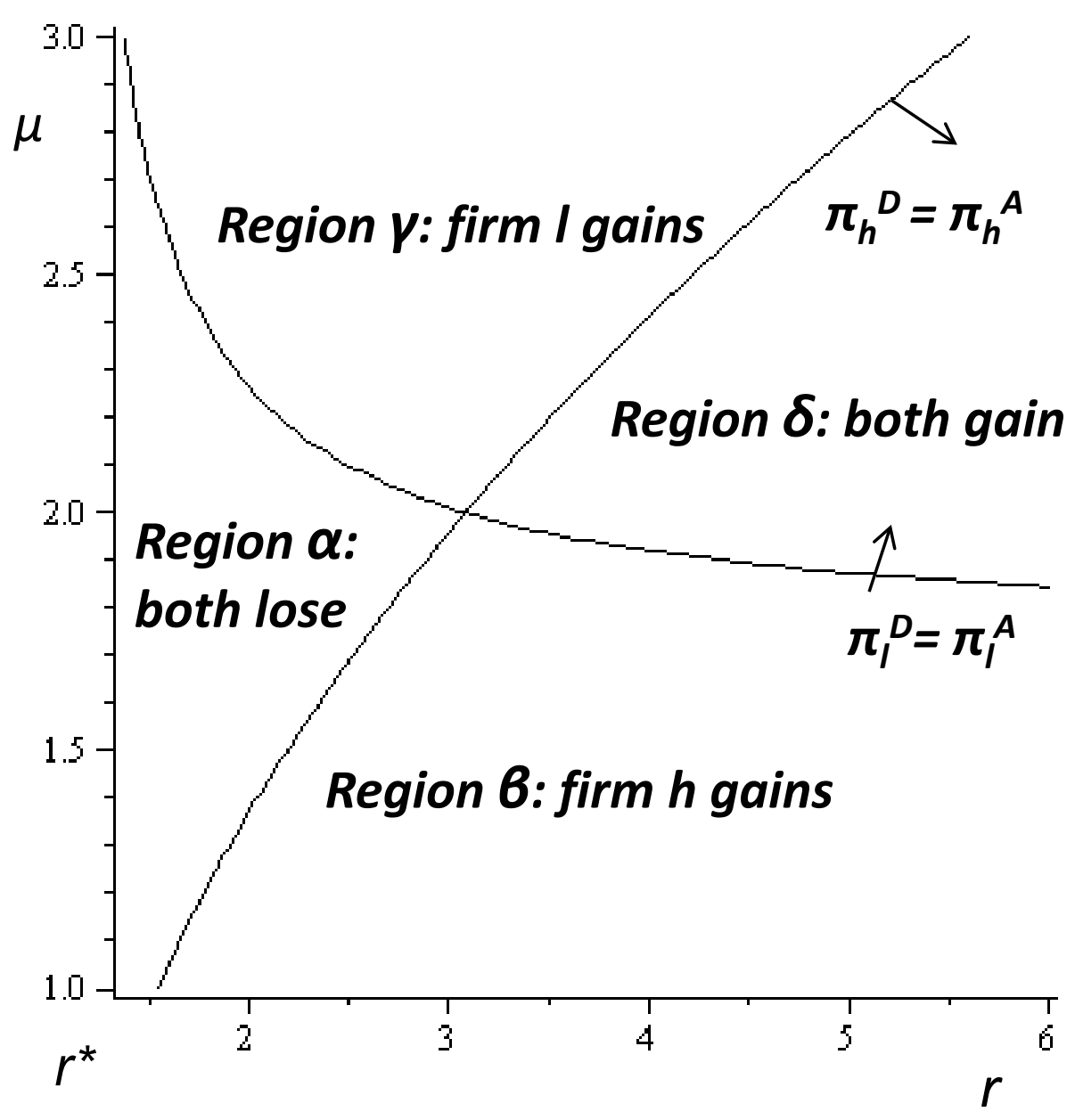

Figure 3: Autarky versus price discrimination 